\title{
Treatments for Chronic Kidney Disease: A Systematic Literature Review of Randomized Controlled Trials
}

\author{
Juan Jose Garcia Sanchez · Juliette Thompson • David A. Scott • \\ Rachel Evans · Naveen Rao · Elisabeth Sörstadius · Glen James • \\ Stephen Nolan · Eric T. Wittbrodt · Alyshah Abdul Sultan • \\ Bergur V. Stefansson · Dan Jackson · Keith R. Abrams
}

Received: October 1, 2021 / Accepted: November 26, 2021 / Published online: December 8, 2021

(C) The Author(s) 2021

\begin{abstract}
Delaying disease progression and reducing the risk of mortality are key goals in the treatment of chronic kidney disease (CKD). New drug classes to augment renin-angiotensin-aldosterone system (RAAS) inhibitors as the standard of care have scarcely met their primary endpoints until recently. This systematic literature review explored treatments evaluated in patients with CKD since 1990 to understand what contemporary data add to the treatment landscape. Eighty-nine clinical trials were identified that had enrolled patients with estimated glomerular filtration rate $13.9-102.8 \mathrm{~mL} /$ $\mathrm{min} / 1.73 \mathrm{~m}^{2}$ and urinary albumin-to-creatinine
\end{abstract}

Supplementary Information The online version contains supplementary material available at https:// doi.org/10.1007/s12325-021-02006-z.

J. J. Garcia Sanchez $(\bowtie) \cdot$ N. Rao · G. James .

S. Nolan · A. Abdul Sultan · D. Jackson BioPharmaceuticals Medical, AstraZeneca, Academy House, 136 Hills Road, Cambridge CB2 8PA, UK e-mail: juanjose.garciasanchez@astrazeneca.com

J. Thompson - D. A. Scott · R. Evans · K. R. Abrams Visible Analytics, Oxford, UK

E. Sörstadius · B. V. Stefansson

BioPharmaceuticals R\&D, AstraZeneca, Gothenburg, Sweden

E. T. Wittbrodt

BioPharmaceuticals Medical, AstraZeneca,

Gaithersburg, MD, USA ratio (UACR) 29.9-2911.0 mg/g, with (75.5\%) and without (20.6\%) type 2 diabetes (T2D). Clinically objective outcomes of kidney failure and all-cause mortality (ACM) were reported in 32 and 64 trials, respectively. Significant reductions $(P<0.05)$ in the risk of kidney failure were observed in seven trials: five small trials published before 2008 had evaluated the RAAS inhibitors losartan, benazepril, or ramipril in patients with $(n=751)$ or without $(n=84-436) \quad$ T2D; two larger trials $(n=2152-2202)$ published onwards of 2019 had evaluated the sodium-glucose co-transporter 2 (SGLT2) inhibitors canagliflozin (in patients with T2D and UACR > 300-5000 mg/g) and dapagliflozin (in patients with or without T2D and UACR $200-5000 \mathrm{mg} / \mathrm{g}$ ) added to a background of RAAS inhibition. Significant reductions in ACM were observed with dapagliflozin in the DAPA-CKD trial. Contemporary data therefore suggest that augmenting RAAS inhibitors with new drug classes has the potential to improve clinical outcomes in a broad range of patients with CKD.

Keywords: Albuminuria; All-cause mortality; Chronic kidney disease; Diabetes; Estimated glomerular filtration rate; Kidney failure 


\section{Key Summary Points}

Why carry out this study?

Morbidity, mortality, and the economic burden from chronic kidney disease (CKD) are growing worldwide.

This systematic literature review examined contemporary clinical trial data relative to the overall CKD treatment landscape to view the impact of novel drug classes following 20 years of little to no innovation.

\section{What was learned from the study?}

Augmenting the standard of care with canagliflozin or finerenone could significantly improve clinical outcomes in patients with type 2 diabetes (T2D).

Augmenting the standard of care with dapagliflozin could significantly improve clinical outcomes regardless of T2D status and is the only agent that has been shown to significantly reduce all-cause mortality risk.

Composite and surrogate endpoints in clinical trials have varied widely over time, likely due to changing guidelines, and may benefit from standardization.

\section{INTRODUCTION}

An estimated 840 million people worldwide have chronic kidney disease (CKD) [1], which was responsible for 1.2 million deaths and 35.8 million disability-adjusted life years in 2017 [2]. However, only 12\% of sufferers are aware of their condition [3]. CKD is diagnosed when the estimated glomerular filtration rate (eGFR) declines below $60 \mathrm{~mL} / \mathrm{min} / 1.73 \mathrm{~m}^{2}$ or the urinary albumin-to-creatinine ratio (UACR) equals or exceeds $30 \mathrm{mg} / \mathrm{g}$ for 3 months or longer [4]. As CKD progresses, healthcare costs increase and health-related quality of life
(HRQoL) diminishes, with the greatest costs and HRQoL burden associated with kidney failure $\left(\mathrm{eGFR}<15 \mathrm{~mL} / \mathrm{min} / 1.73 \mathrm{~m}^{2}\right) \quad[5,6]$. Adverse clinical outcomes, healthcare utilization and costs, and disease burden also increase as albuminuria worsens [7-9], and UACR 30-300 mg/g (moderately increased) and even $>300 \mathrm{mg} / \mathrm{g}$ (severely increased) are now considered important predictors of risk for CKD progression, cardiovascular events, and mortality [4]. Early identification and pharmacologic intervention could therefore delay or prevent CKD progression.

Current guidelines recommend using renin-angiotensin-aldosterone system (RAAS) inhibitors (either an angiotensin-converting enzyme inhibitor or an angiotensin receptor blocker) to delay or prevent CKD progression [4]. Clinical trials of other drug classes to augment RAAS inhibitors, delay progression, and improve outcomes have scarcely met their primary endpoints [10], except for sodium-glucose co-transporter 2 (SGLT2) inhibitors. Initially developed as blood glucose-lowering agents, reports of renal and cardiovascular benefits in patients with type 2 diabetes (T2D) [11-14] as well as cardiovascular benefits in patients with heart failure (HF) [15-17] have prompted the evaluation of SGLT2 inhibitors in patients with $\mathrm{CKD}$ who are already receiving standard of care treatment with RAAS inhibitors.

This systematic literature review explored the treatments evaluated in patients with CKD since 1990 to allow an assessment of contemporary data relative to the overall treatment landscape.

\section{METHODS}

This systematic literature review was conducted according to the recommendations of Cochrane [18], the Centre for Reviews and Dissemination [19], and the National Institute for Health and Care Excellence [20]. The protocol has been registered on PROSPERO (CRD42020190152).

This article is based on previously conducted studies and does not contain any new studies with human participants or animals performed by any of the authors. 


\section{Data Sources and Searches}

Using the terms listed in the Supplementary Material, we searched MEDLINE, Embase, and the Cochrane Library for peer-reviewed articles published between 1990 and November 2, 2020, that reported results from prospective, paralleldesign randomized controlled trials that evaluated pharmacologic treatments for patients aged 18 years or more with CKD and albuminuria. Search filters for MEDLINE and Embase were obtained from the Scottish Intercollegiate Guideline Network [21], and adapted for Embase by Cochrane [22]. In line with guidelines for the inclusion of gray literature [18-20, 23], the proceedings of key international conferences and trial registries were also searched (Supplementary Material).

Non-English-language publications, reviews, case studies, case reports, conference proceedings (other than those identified in the search described above), and animal studies were excluded.

\section{Trial Selection}

After removing duplicates from the combined search results, two independent reviewers screened the identified abstracts against predefined eligibility criteria (Table 1). Abstracts deemed eligible for inclusion were then compared and any discrepancies resolved mutually or by a third reviewer. This independent double-review process was repeated on the full-text articles to identify a final list of trials eligible for inclusion in this review.

\section{Data Extraction and Quality Assessment}

Data were extracted by one reviewer and validated by a second, with disagreements resolved by a third (Supplementary Material). Binary variables included trial population, number or proportion of patients experiencing an event, and incidence rates per population or persontime. Continuous and time-to-event variables included hazard ratio (HR), odds ratio, relative risk, mean, median, standard deviation, standard error, range, 95\% confidence interval (CI), interquartile range, and $P$ value. Outcomes reported without $P$ values or $95 \%$ CIs were assumed not to be statistically significant. Outcomes reported with $P<0.05$ or with $95 \%$ CIs not crossing 1.0 for a HR or relative risk were assumed to be statistically significant.

Risk of bias and quality of reporting were assessed using eight questions from the PMG24 Company Evidence Submission Template (NICE single technology appraisal process) [24], developed based on previous recommendations [19]. Answers of "yes," "no," or "unclear due to inadequate reporting" were required. Depending on the question, answers of "yes" or "no" could indicate a higher or lower risk of bias (Supplementary Material).

\section{Compliance with Ethics Guidelines}

This article is based on previously conducted studies and does not contain any new studies with human participants or animals performed by any of the authors.

\section{RESULTS}

\section{Search Results}

Overall, 40,550 records were identified (Fig. 1). After removal of 20,773 duplicates, 19,777 abstracts were reviewed against eligibility criteria, and 19,557 were excluded. The full texts of 220 articles were reviewed, and 121 were excluded (Table S1). The addition of one more article, identified during a search of conference proceedings, resulted in 100 eligible articles providing data for 89 randomized controlled trials (Table 2).

\section{Trial Characteristics}

Thirty-seven trials were multinational, 18 were conducted in Japan, and seven each were conducted in China and Italy, with the remaining trials conducted in a range of countries worldwide.

Sixty-six trials $(74.2 \%)$ were published onwards of 2010, and 23 (25.8\%) were 
Table 1 Eligibility criteria

\begin{tabular}{|c|c|c|}
\hline & Inclusion & Exclusion \\
\hline Population & $\begin{array}{l}\text { Adults aged } \geq 18 \text { years with CKD and } \\
\text { albuminuria, }{ }^{\text {a,b,c }} \text { with or without } \mathrm{T} 2 \mathrm{D}\end{array}$ & $\begin{array}{l}\text { Subjects without CKD or with an acute kidney } \\
\text { injury (note that acute kidney injury in subjects } \\
\text { with CKD is an outcome of interest in the } \\
\text { DAPA-CKD trial) } \\
\text { According to DAPA-CKD eligibility criteria, } \\
\text { subjects with CKD were excluded if they met one } \\
\text { or more of the following criteria: } \\
\text { Type } 1 \text { diabetes } \\
\text { Organ transplantation (any organ, including } \\
\text { kidneys) } \\
\text { Receiving dialysis } \\
\text { Polycystic kidney disease (any type), lupus } \\
\text { nephritis, or anti-neutrophil cytoplasmic } \\
\text { antibody-associated vasculitis } \\
\text { New York Heart Association class IV congestive } \\
\text { heart failure } \\
\text { Malignancies } \\
\text { Blood-borne diseases (e.g., HIV, hepatitis) }\end{array}$ \\
\hline Intervention/comparators & $\begin{array}{l}\text { Pharmacological agents for the treatment } \\
\text { of CKD } \\
\text { Placebo }\end{array}$ & $\begin{array}{l}\text { Treatments for secondary conditions associated } \\
\text { with CKD (e.g., anemia, mineral and bone } \\
\text { disorder) } \\
\text { Non-pharmacological treatments (e.g., devices, } \\
\text { diagnostics, transplants, dialysis) } \\
\text { As per DAPA-CKD eligibility criteria, cytotoxic } \\
\text { therapy }\end{array}$ \\
\hline Outcomes & $\begin{array}{l}\text { Clinical outcomes (see Data extraction } \\
\text { variables in the Supplementary } \\
\text { Material) } \\
\text { Adverse events } \\
\text { Health-related quality of life } \\
\text { Patient-reported outcomes }\end{array}$ & $\begin{array}{l}\text { Pharmacokinetics } \\
\text { Pharmacodynamics }\end{array}$ \\
\hline
\end{tabular}


Table 1 continued

\begin{tabular}{|c|c|c|}
\hline & Inclusion & Exclusion \\
\hline Study type & $\begin{array}{l}\text { Prospective, parallel-design, phase } 3-4 \\
\text { RCTs (only publications reporting the } \\
\text { randomization phase) }\end{array}$ & $\begin{array}{l}\text { Any trials using a crossover design } \\
\text { Any trials described as pilot studies } \\
\text { Any non-randomized studies, including (but not } \\
\text { limited to) parallel non-randomized clinical trials, } \\
\text { single-arm clinical trials, case studies and reports, } \\
\text { and any observational studies } \\
\text { Reviews, including systematic literature reviews } \\
\text { Editorials, letters, and commentaries }\end{array}$ \\
\hline \multirow[t]{3}{*}{ Others } & Language: English & Other languages \\
\hline & $\begin{array}{l}\text { Publication years: } 1990 \text { to November 2, } \\
2020\end{array}$ & Older publications \\
\hline & $\begin{array}{l}\text { Study duration: } \geq 12 \text { weeks } \\
\geq 50 \text { patients per randomized arm }\end{array}$ & \\
\hline
\end{tabular}

$C K D$ chronic kidney disease, $H I V$ human immunodeficiency virus, $R C T$ randomized controlled trial, T2D type 2 diabetes ${ }^{a}$ Including proxies: albumin-to-creatinine ratio, urinary protein-to-creatinine ratio, or reagent strip qualitative recording

${ }^{b}$ This was required to be reported in the trial eligibility criteria or as a baseline characteristic; trials were excluded if no information on albuminuria was reported or if patients with severely increased albuminuria were explicitly excluded from the trial

${ }^{\mathrm{c}}$ Albuminuria could be reported using multiple methods

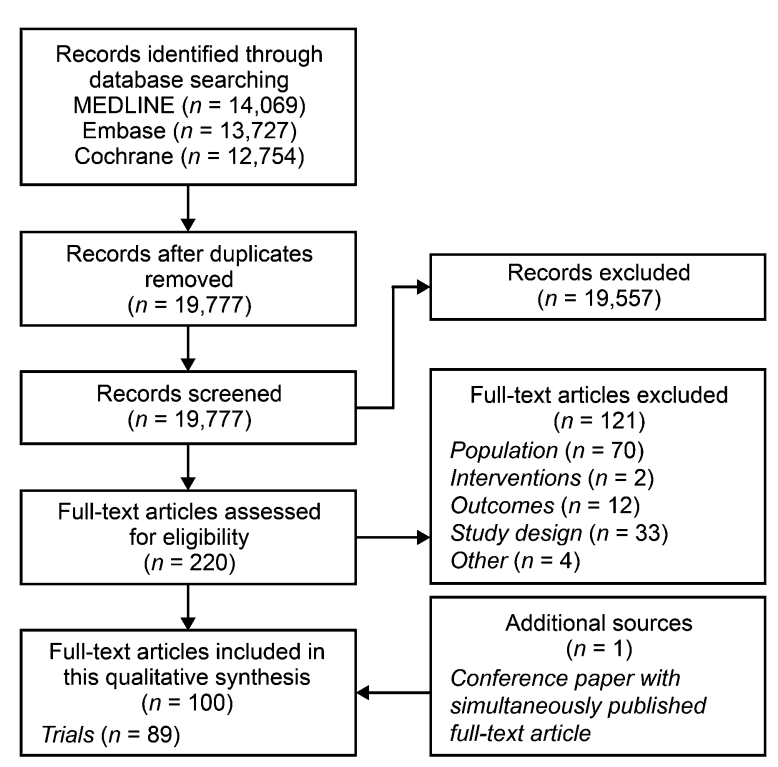

Fig. 1 Study selection PRISMA diagram published before 2010. Forty-three trials $(48.3 \%)$ were phase $3(n=29)$, phase $4(n=10)$, phase $2 / 3(n=3)$, or phase $3 / 4(n=1)$, and most were double blind (61.8\%) or open label (32.6\%) (Fig. S1a, b). Forty-six trials (51.7\%) did not report their trial phase.

Most trials enrolled 50-100 patients per arm, although 10 conducted onwards of 2004 enrolled more than 1000 patients per arm [25-27, 34, 47, 60, 73-75, 93]. Forty-three trials (48.3\%) enrolled patients with T2D, 29 enrolled patients with or without T2D (32.6\%), and 17 enrolled patients without T2D (19.1\%). Across all included trials, $75.5 \%$ of patients had T2D (Fig. S2a, b). All patients were followed for at least 12 weeks, although mean or median follow-up extended to at least 12 months in 60 trials (67.4\%) and at least 24 months in 38 trials (42.7\%). 


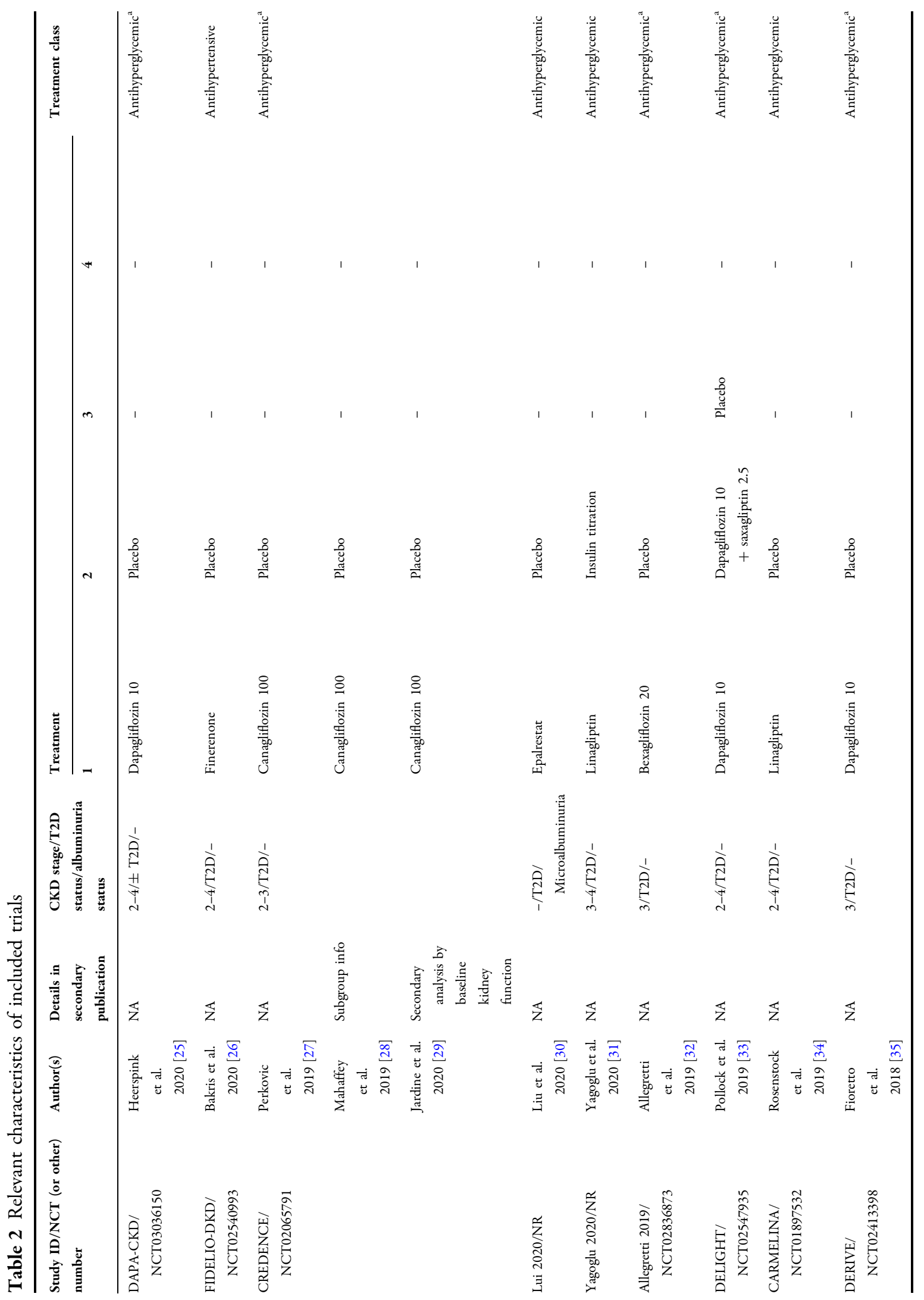




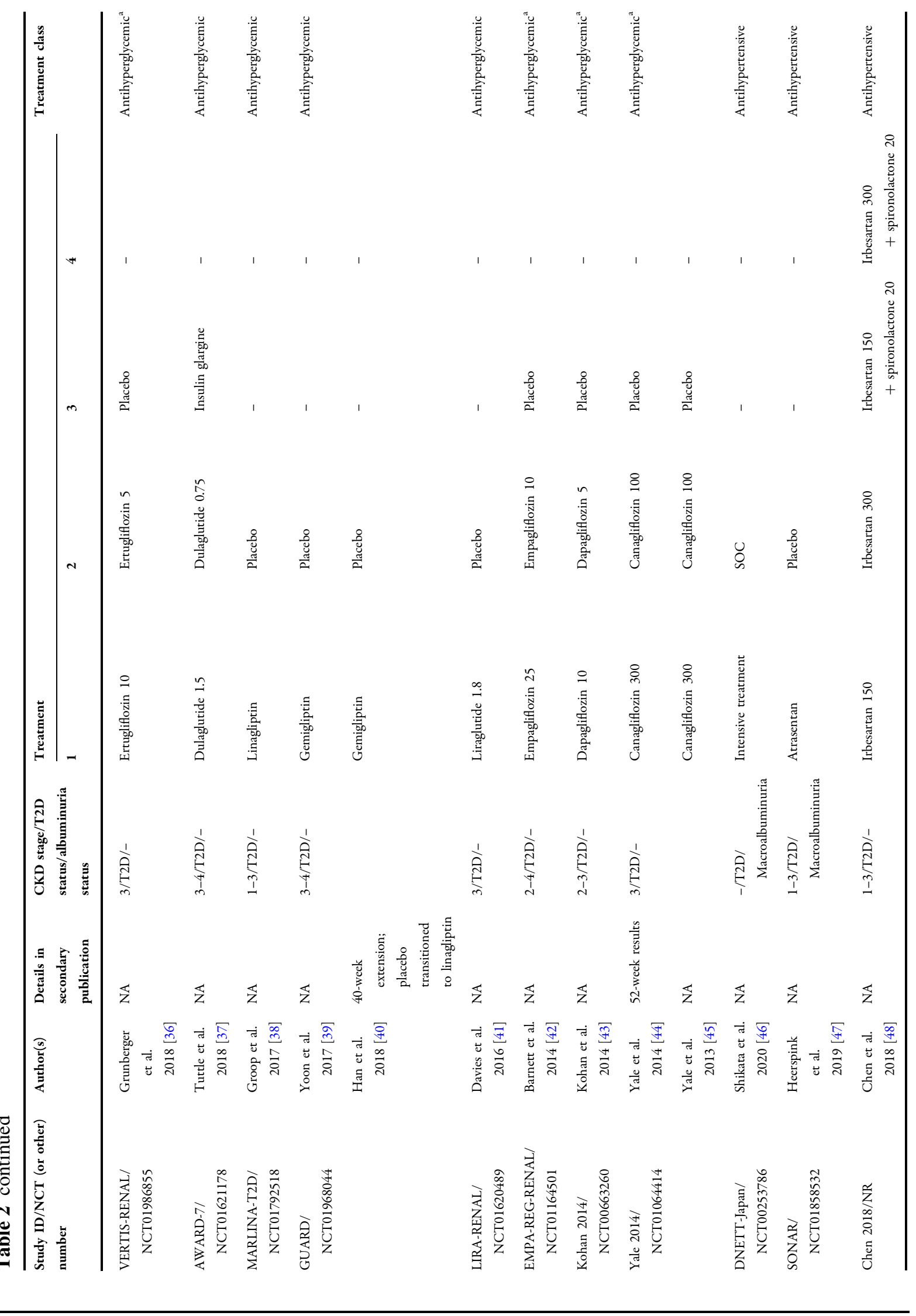




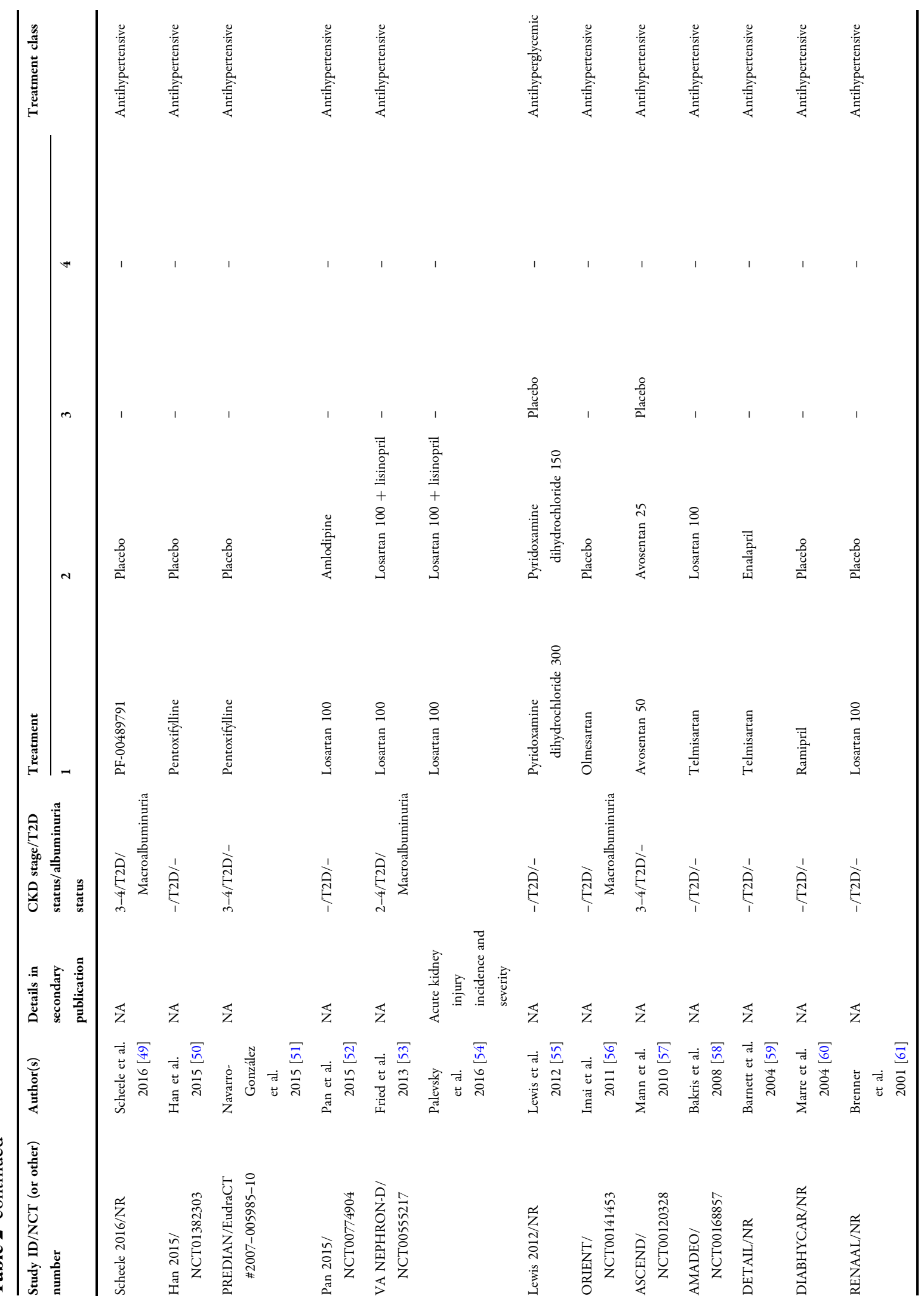




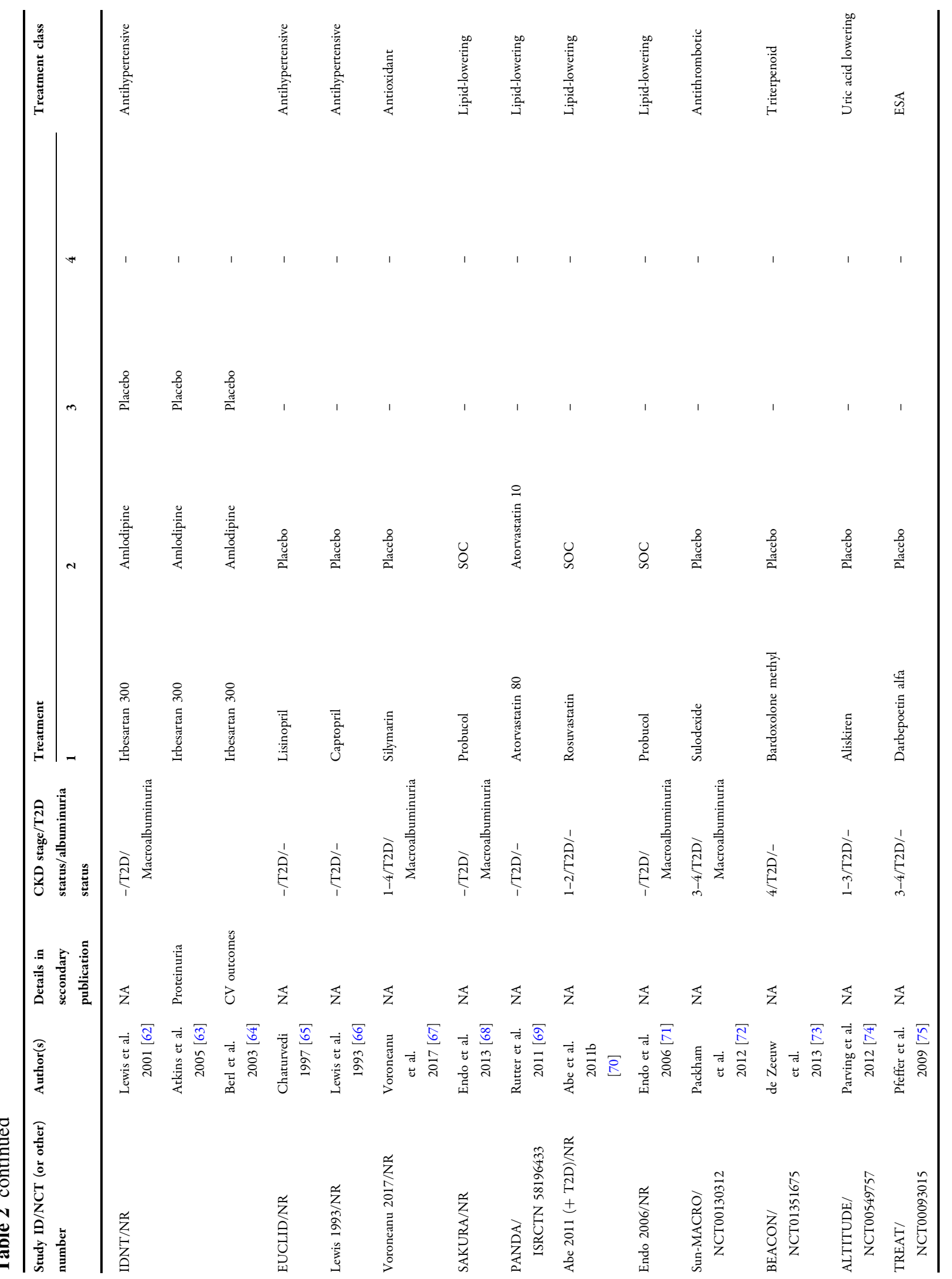




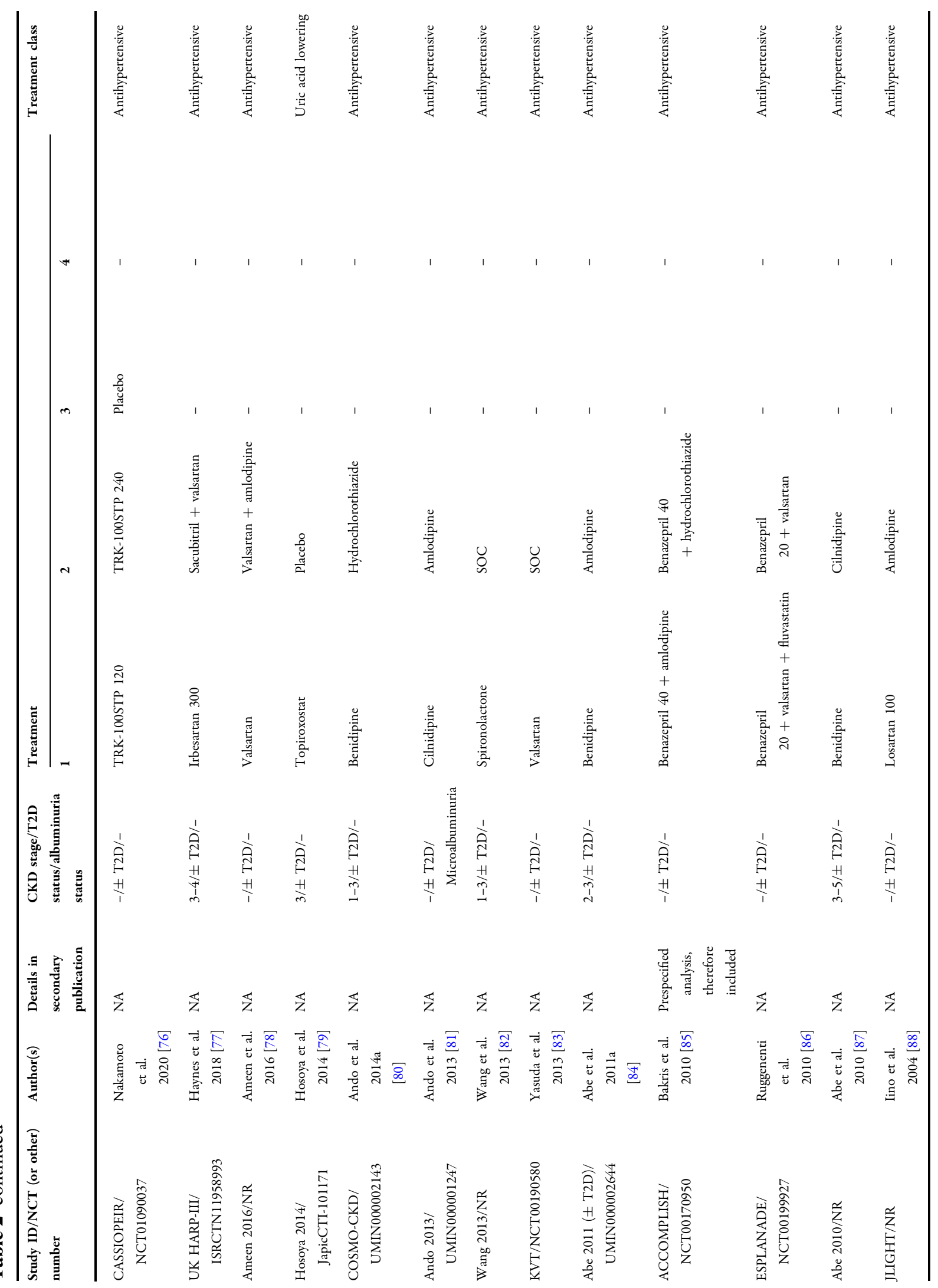




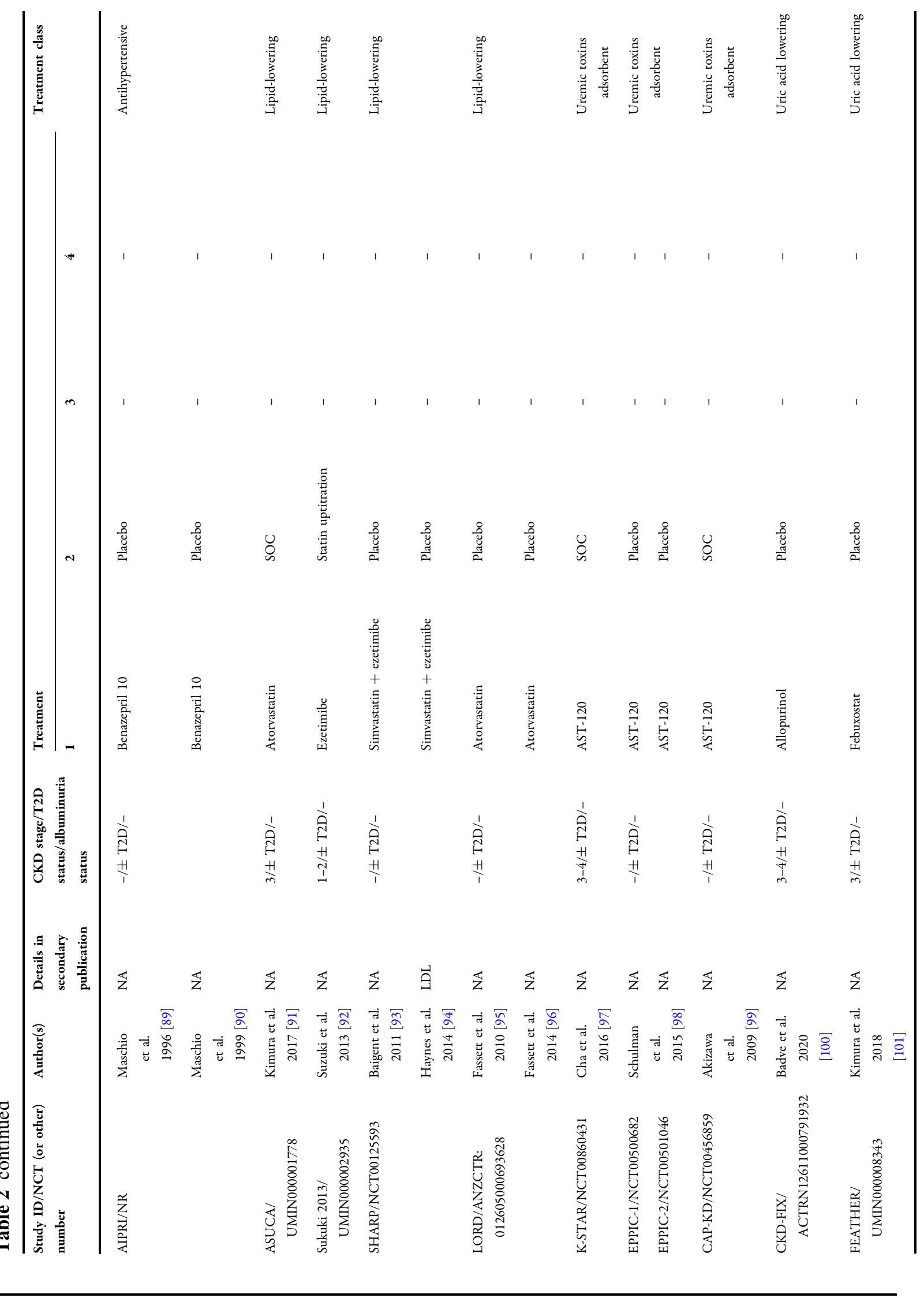




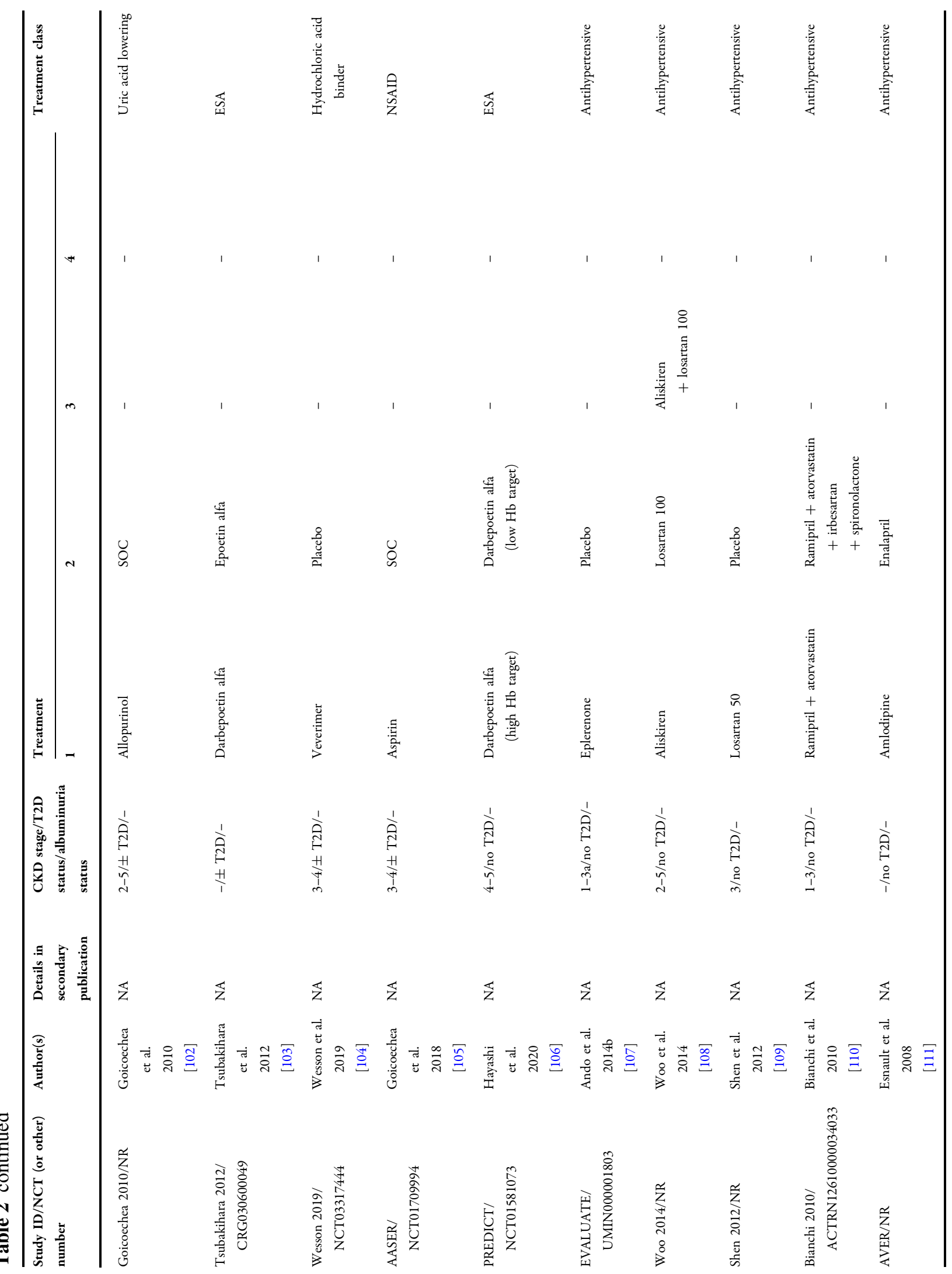




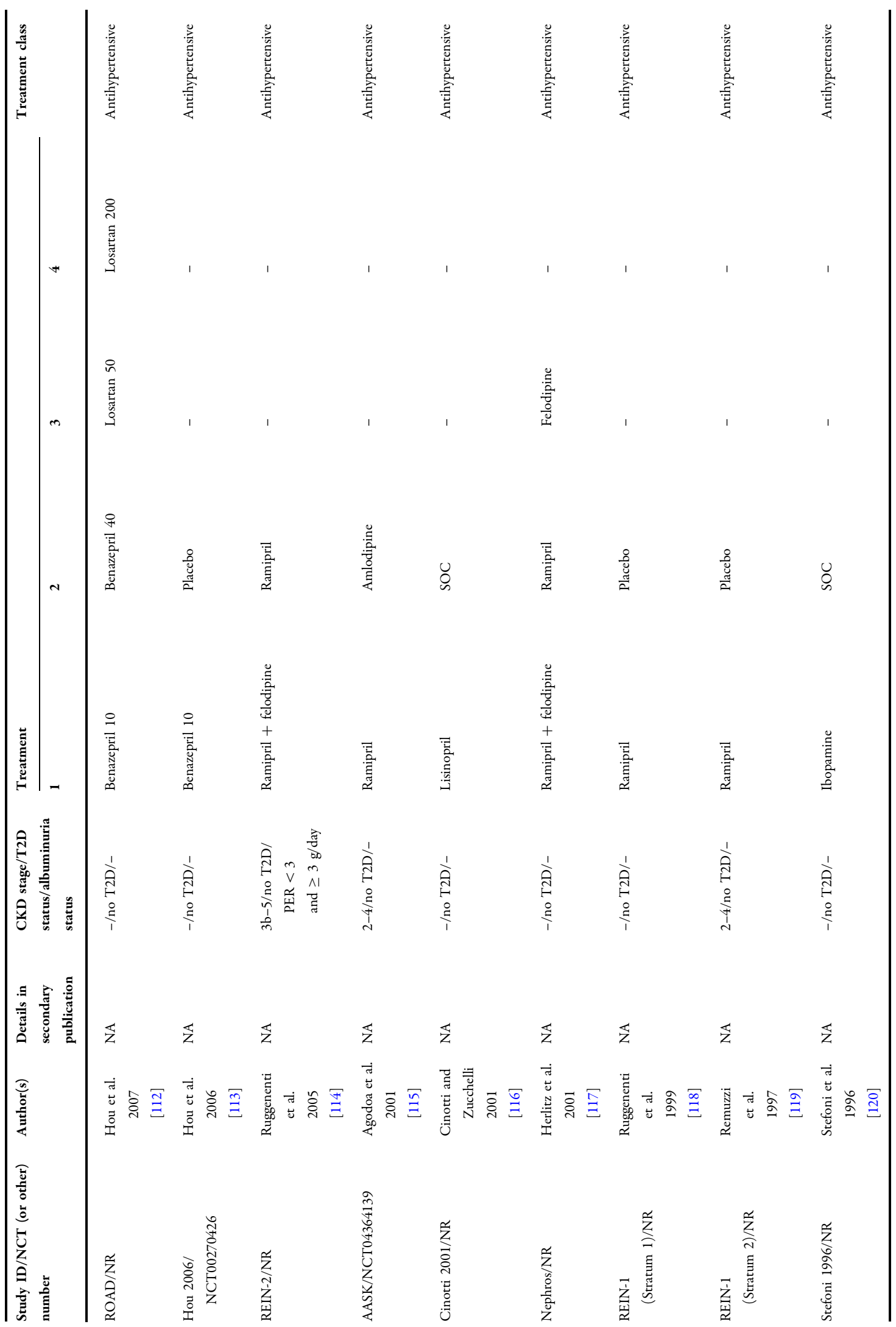




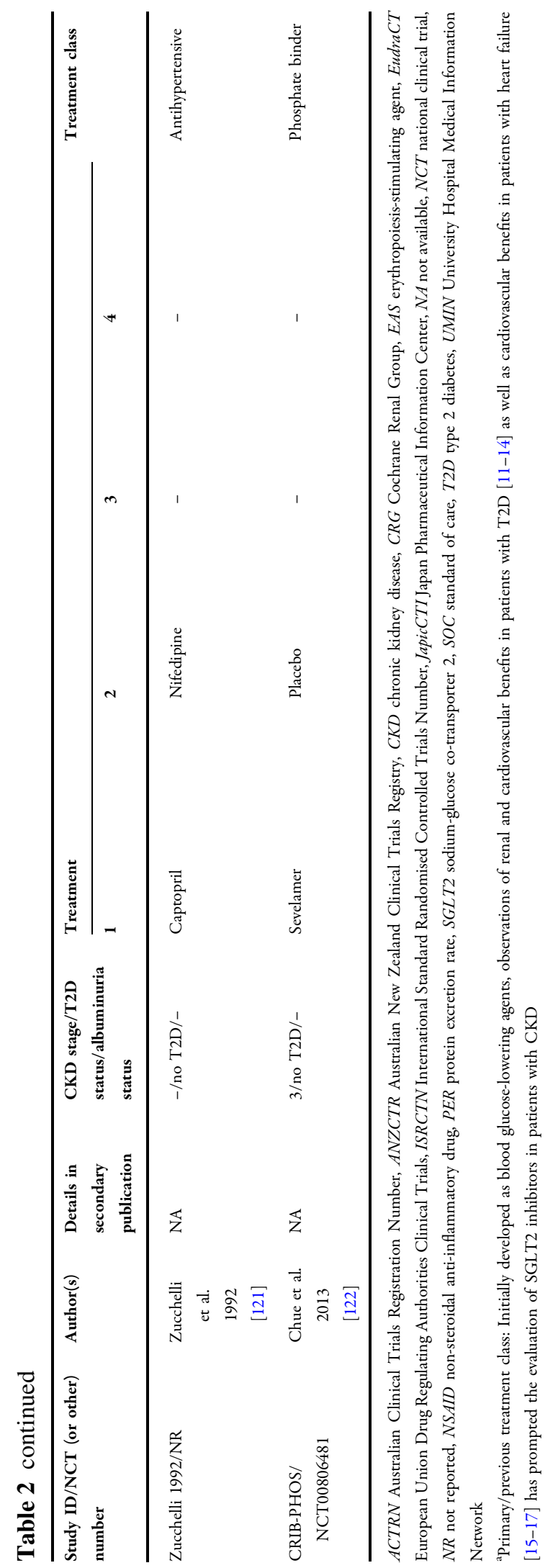


Antihypertensive agents were the most common intervention assessed overall, but were approximately twice as common in trials of patients without T2D (88\%) than trials of patients with $(42 \%)$, or with or without $(45 \%)$ T2D. Blood glucose-lowering agents were also common in trials of patients with T2D (37\%). The most common comparators were placebo in trials of patients with T2D (53\%) and active comparators in trials of patients without (53\%), or with or without (38\%) T2D. Placebo was also common in trials of patients without (35\%), or with or without (34\%) T2D (Fig. S3a, b).

\section{Baseline Patient Characteristics}

In more than $80 \%$ of trials, $50-100 \%$ of patients were male (Fig. S4). Mean age ranges were 51.0-72.1 years in trials of patients with or without T2D (except one trial with a mean age range of $34-35$ years [82]), 53.8-70.2 years in trials of patients with T2D (except one trial with a mean age range of 34.0-35.0 years [66], and one trial with a median age of 33 years [65]), and 44.4-71.0 years in trials of patients without T2D.

While CKD etiologies other than diabetic nephropathy were infrequently reported in trials of patients with T2D, 13 trials (14.6\%) of patients without T2D and 16 (18.0\%) of patients with or without T2D reported glomerulonephritis as a key CKD etiology (Table S2a, b).

Mean eGFR ranged between 13.9 and $102.8 \mathrm{~mL} / \mathrm{min} / 1.73 \mathrm{~m}^{2}$, including two trials that enrolled patients with mean eGFR $>90 \mathrm{~mL} / \mathrm{min} / 1.73 \mathrm{~m}^{2}$ (Table S3) $[38,59]$. Trials most commonly reported albuminuria as UACR (50.6\%), with mean UACR ranging between 29.9 and $2911.0 \mathrm{mg} / \mathrm{g}$. Other trials reported UACR via categorization into normo-, micro-, or macroalbuminuria (16.9\%), albumin excretion rate $(12.4 \%)$, protein excretion rate (20.2\%), protein-to-creatinine ratio $(18.0 \%)$, or urinary albumin value (13.5\%) (Table S4a-f).

Thirty-one trials $(34.8 \%)$ included patients with prior histories of cardiovascular disease, with the proportion of patients ranging from $1.7 \%$ to $92.0 \%$, although cardiovascular disease history was either inconsistently defined or not defined at all (Table S5). Fourteen trials (15.7\%) included patients with HF, with the proportion of patients ranging from $0.6 \%$ to $43.1 \%$ (Table S6). Eighty-two trials (92.1\%) reported systolic and diastolic blood pressure (Table S7).

\section{Composite Outcomes}

Fifty-seven composite endpoints were identified, only 13 of which were used in more than one trial (Fig. S5a, b). Composite outcomes are summarized in Table S8.

Twelve trials (13.5\%) reported significant reductions in the risks of composites comprising kidney failure plus one or more of doubling of serum creatinine, eGFR reduction $(\geq 40 \%$ or $\geq 50 \%$ ), mortality (all-cause, renal, or cardiovascular), myocardial infarction (MI), stroke, albuminuria progression, or other (Table 3). These included trials published before 2013 evaluating RAAS inhibitors losartan (RENAAL, ROAD) [61, 112], ramipril (REIN-1, AASK) [115, 123], irbesartan (IDNT) [62], valsartan (KVT) [83], and benazepril (ROAD, and an unnamed trial) $[112,113]$ in patients with, without, or with or without T2D. Also included were trials published onwards of 2019 evaluating dipeptidyl peptidase 4 inhibitor linagliptin (CARMELINA) [34], endothelin A receptor antagonist atrasentan (SONAR) [47], and the non-steroidal mineralocorticoid receptor antagonist finerenone (FIDELIO-DKD) [26] in patients with T2D, as well as the SGLT2 inhibitor canagliflozin (CREDENCE) [27] in patients with T2D and UACR $>300-5000 \mathrm{mg} / \mathrm{g}$. Another SGLT2 inhibitor, dapagliflozin, significantly reduced the risk of composite endpoints comprising kidney failure and at least 50\% eGFR reduction plus cardiovascular and/or renal mortality in patients with or without T2D and UACR 200-5000 mg/g (DAPA-CKD) [25]. Kidney failure as an independent outcome is reported below.

Four trials $(4.5 \%)$ reported significant reductions in the risks of composites comprising cardiovascular mortality without kidney failure, plus at least one of doubling serum creatinine, renal mortality, MI, stroke, hospitalization for $\mathrm{HF}$, or hospitalization for HF or unstable angina 


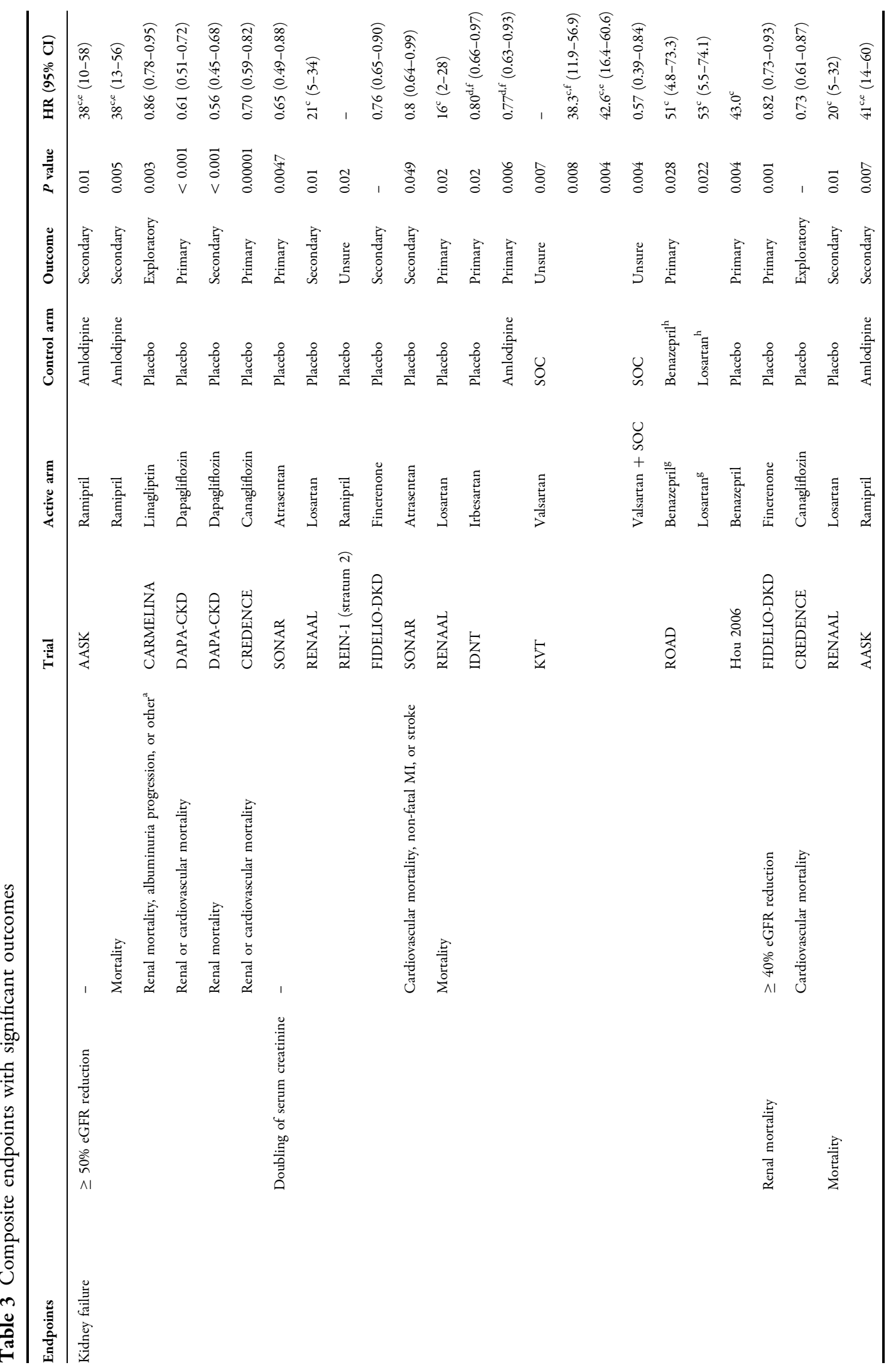




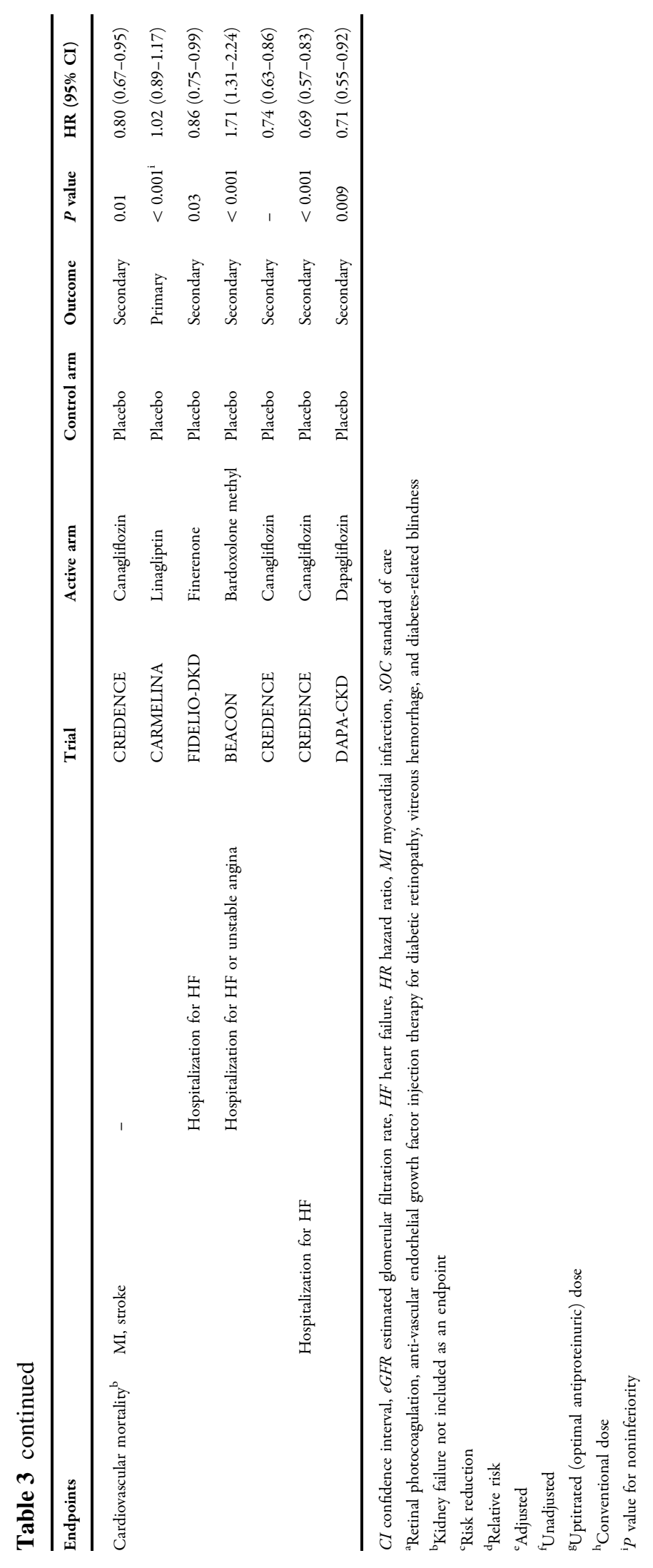


(Table 3). These included the CARMELINA [34], FIDELIO-DKD [26], and CREDENCE [27] trials, as well as the DAPA-CKD trial of dapagliflozin, which significantly reduced the risk of a composite endpoint comprising cardiovascular mortality and hospitalization for HF [25]. Conversely, the risk of a composite endpoint comprising cardiovascular mortality and hospitalization for $\mathrm{HF}$ or unstable angina increased in the BEACON trial of bardoxolone methyl, a nuclear 1 factor (erythroid-derived 2)related factor 2 activator, although patients in this trial had CKD stage 4, T2D, and median UACR $320 \mathrm{mg} / \mathrm{g}$ [73].

\section{Renal Outcomes}

\section{Kidney Failure}

Kidney failure (previously end-stage kidney disease or end-stage renal disease [124]) ensues when eGFR declines below $15 \mathrm{~mL} / \mathrm{min} / 1.73 \mathrm{~m}^{2}$ (CKD stage 5) and the patient requires kidney replacement therapy (previously renal replacement therapy [124]) in the form of a transplant or dialysis [4].

Thirty-two trials $(36.0 \%)$ reported numbers of patients progressing to kidney failure (Table S9). Significant risk reductions were observed in seven trials (7.9\%): the RENAAL trial of losartan in patients with T2D and $\mathrm{UACR} \geq 300 \mathrm{mg} / \mathrm{g}(P=0.002)$ [61], the ROAD trial of optimal antiproteinuric doses of losartan $(P=0.046)$ and benazepril $(P=0.042)$ in patients without T2D [112], an unnamed trial of conventionally dosed benazepril in patients without T2D $(P=0.02)$ [113], the REIN-1 and AASK trials of ramipril in patients without T2D (both $P=0.01$ ) $[115,118]$, the CREDENCE trial of canagliflozin $(P=0.002)$ [27], and the DAPACKD trial of dapagliflozin (HR 0.64; 95\% CI 0.50-0.82) [25].

\section{Dialysis and Transplantation}

Dialysis, kidney transplantation, or both were reported in $17(19.1 \%)$, seven (7.9\%), and two trials $(2.2 \%)$, respectively (Table S10). Significant outcomes were limited to three trials (3.4\%). The lipid-lowering agent probucol lengthened mean time to starting dialysis in a trial of patients with T2D and UACR $>300 \mathrm{mg} /$ $\mathrm{g}(P=0.009)[71]$, and the number of patients starting dialysis was significantly reduced in a trial of patients without T2D receiving the RAAS inhibitor captopril $(P<0.005)$ [121], as well as patients receiving dapagliflozin in the DAPACKD trial (HR 0.66; 95\% CI 0.48-0.90) [25].

\section{Kidney Function Decline}

Percentage eGFR declines, mean eGFR declines, and final eGFR measurements at end of followup were reported in $11(12.4 \%), 30$ (33.7\%), and $25(28.1 \%)$ trials, respectively (Table S11a-c).

The number of patients reaching an eGFR decline of $50 \%$ was significantly reduced in four trials $(4.5 \%)$ : the SONAR trial of atrasentan in patients with T2D and UACR $300-5000 \mathrm{mg} / \mathrm{g}$ $(P=0.038)$ [47], the LORD trial of lipid-lowering agent atorvastatin in patients with or without T2D $(P=0.023)$ [95], and the DAPA-CKD trial of dapagliflozin (HR 0.53; 95\% CI 0.42-0.67) [25]. In the PREDICT trial of erythropoiesis-stimulating agent darbepoetin alfa, the number of patients without T2D reaching an eGFR decline of $50 \%$ was also significantly reduced among those targeting a higher (11-13 g/dL) versus lower $(9-11 \mathrm{~g} / \mathrm{dL})$ hemoglobin level $(P=0.008)$; however, targeting a higher hemoglobin level did not improve kidney outcomes overall [106]. The number of patients reaching an eGFR decline of at least $40 \%$ was significantly reduced in the FIDELIODKD trial of finerenone (HR 0.81; 95\% CI $0.72-0.92)$ [26].

Twenty trials (22.5\%) reported numbers of patients doubling their serum creatinine (Table S12). Significant risk reductions were observed in seven trials (7.9\%): the SONAR trial of atrasentan $(P=0.0055)$ [47], the FIDELIODKD trial of finerenone (HR 0.68; 95\% CI 0.55-0.82) [26], the RENAAL trial of losartan $(P=0.006)$ [61], the ROAD trial of optimal antiproteinuric doses of losartan $(P=0.040)$ and benazepril $(P=0.041)$ [112], an unnamed trial of conventional doses of benazepril $(P=0.02)$ [113], the IDNT trial of irbesartan $(P<0.001$ vs amlodipine, $P=0.003$ vs placebo $)$ [62], and the CREDENCE trial of canagliflozin $(P<0.001)$ [27]. 


\section{Cardiovascular Outcomes}

\section{Heart Failure}

Fourteen trials $(15.7 \%)$ reported incidences of HF (Table S13), with significant reductions observed in two trials (2.2\%): the ASCEND trial of endothelin type A receptor antagonist avosentan in patients with T2D $(P=0.008$ with a 25-mg dose, $P=0.05$ with a 50-mg dose) [57] and the IDNT trial of irbesantan $(P=0.004$ vs amlodipine, $P=0.048$ vs placebo) [64].

\section{Hospitalization for HF or Unstable Angina}

Hospitalization for HF and hospitalization for unstable angina were reported in 10 (11.2\%) and two trials (2.2\%), respectively (Table S14). Significant reductions in hospitalization for HF were observed in two trials (2.2\%): the RENAAL trial of losartan $(P=0.005)$ [61] and the CREDENCE trial of canagliflozin $(P<0.001)$ [27]. Conversely, bardoxolone methyl significantly increased hospitalization for HF in the BEACON trial $(P<0.001)$ [73].

\section{MI and Stroke}

Twenty-four trials (27.0\%) reported acute, nonfatal, or fatal MI, and 25 trials (28.1\%) reported non-fatal or fatal stroke (Tables S15 and S16). A significant reduction in MI was observed in patients receiving the calcium channel blocker amlodipine in the IDNT trial $(P=0.021$ vs placebo) [64]. A significant reduction in non-fatal stroke was observed in the SONAR trial of atrasentan $(P=0.0021)$ [47], and significant reductions in ischemic $(P=0.0073)$ or any stroke $(P=0.01)$ were observed in the SHARP trial of a combination of lipid-lowering agents simvastatin and ezetimibe in patients with or without T2D [93]. Conversely, a significant increase in fatal or non-fatal stroke was observed in the TREAT trial of patients with CKD stages 3-4 and T2D receiving darbepoetin alfa $(P<0.001)$ [75].

\section{Mortality Outcomes}

\section{All-Cause Mortality}

Sixty-three trials (70.8\%) reported all-cause mortality (ACM) (Table S17), with a significant reduction observed in the DAPA-CKD trial of dapagliflozin $(P=0.004)$ [25].

\section{Cardiovascular and Renal Mortality}

Cardiovascular and renal mortality were reported in 18 (20.2\%) and nine trials (10.1\%), respectively, with no significant outcomes observed (Table S18).

\section{Other Renal Outcomes}

\section{eGFR Slopes}

eGFR slopes were reported in 15 trials (16.9\%), with eGFR declines significantly reduced in three trials (3.4\%): the RENAAL trial of losartan $(P=0.01)$ [61], an unnamed trial of benazepril $(P=0.006)$ [113], and the REIN-1 trial of ramipril $(P=0.036)[118]$ (Table S19).

\section{Albuminuria}

UACR changes from baseline and final UACR measurements at end of follow-up were reported in 20 (22.5\%) and 17 (19.1\%) trials, respectively (Table S20a, b). Significant UACR decreases from baseline were observed in eight trials (9.0\%): the GUARD, ASCEND, AWARD-7 and EMPA-REGRENAL trials of dipeptidyl peptidase 4 inhibitor gemigliptin $(P<0.001)$ [39], avosentan 25 or $50 \mathrm{mg}(P<0.001)$ [57], glucagon-like peptide-1 receptor agonist dulaglutide $1.5 \mathrm{mg}(P=0.0024)$ [37], and the SGLT2 inhibitor empagliflozin $25 \mathrm{mg}(P=0.0257-0.0031)$ [42], respectively, in patients with T2D; unnamed trials of calcium channel blocker benidipine $(P<0.0001$ vs amlodipine) [84] and xanthine oxidase inhibitor topiroxostat $(P=0.0092)$ [79] in patients with or without T2D; the ACCOMPLISH trial of a combination of benazepril and amlodipine ( $P=0.0001$ vs benazepril combined with hydrochlorothiazide) in patients with or without T2D [85]; and the EVALUATE trial of selective aldosterone antagonist eplenerone in patients without T2D $(P=0.0222)$ [107].

When final UACR measurements at end of follow-up were used, significant decreases in UACR from baseline were observed in four trials (4.5\%): an unnamed trial of lipid-lowering agent rosuvastatin in patients with T2D $(P<0.01$ vs standard of care) [70], the AMADEO 
trial of RAAS inhibitors telmisartan and losartan in patients with T2D (both $P<0.0001$ ) [58], the RENAAL trial of losartan $(P<0.001)$ [61], and an unnamed trial of benidipine $(P<0.01$ vs amlodipine) in patients with or without T2D [84].

\section{Health-Related Quality of Life}

Five trials $(5.6 \%)[75,97,99,100]$ reported HRQoL during treatment. In one trial (1.1\%), Kidney Disease and Quality of Life physical function score improved significantly from baseline $(P<0.0001)$ in patients with CKD and metabolic acidosis treated with veverimer, a first-in-class hydrochloric acid binder [104].

\section{Early Trial Discontinuation}

Ten trials (11.8\%) were stopped early due to low recruitment or low event rates $(n=2)[47,100]$, safety concerns $(n=5)$ [53, 57, 73, 74, 115], negative results reported in a sister trial $(n=1)$ [72], other reasons $(n=1)$ [61], or for reasons not provided $(n=1)$ [113]. On the advice of independent data monitoring committees, the CREDENCE [27] and DAPA-CKD [25] trials were stopped early after meeting prespecified efficacy criteria for early cessation and after demonstrating overwhelming efficacy, respectively.

\section{Risk of Bias Assessment}

For seven of eight questions, $65-100 \%$ of trials had a "lower" or "unclear" risk of bias, while $35 \%$ of trials were not double blind and therefore at a "higher" risk of bias. Potential conflicts of interest were identified in $57 \%$ of trials (Fig. S6a, b).

\section{Safety}

Key safety outcomes are provided in Table S21.

The highest overall incidence of treatmentrelated adverse events (AEs) was reported in a trial of phosphodiesterase type 5 inhibition for patients with diabetic nephropathy (active arm, 54.7\%; placebo arm, 56.3\%) [49]. In this trial, the most common treatment-related AEs occurred in the placebo arm, and included headache $(7.8 \%)$, diarrhea $(3.6 \%)$, dyspepsia (3.6\%), and peripheral edema (1.6\%) [49].

The highest overall incidence of serious AEs was reported in the TREAT trial of darbepoetin alfa (active arm, 61.6\%; placebo arm, 60.4\%), which was stopped early due to safety concerns [75]. The most common serious AE, reported in the placebo arm, was hypertension (24.5\%) [75].

\section{DISCUSSION}

The 89 clinical trials identified by this systematic literature review included a broad range of patients with any stage of CKD (eGFR 13.9-102.8 $\mathrm{mL} / \mathrm{min} / 1.73 \mathrm{~m}^{2}$ ) and albuminuria (UACR $29.9-2911.0 \mathrm{mg} / \mathrm{g}$ ), with $(75.5 \%)$ or without (20.6\%) T2D.

Many trials evaluated the impact of treatment on one or more composite endpoints, and 16 trials reported significant reductions in risks of composites comprising kidney failure $(n=12)$ or cardiovascular mortality without kidney failure $(n=4)$ while evaluating RAAS inhibitors, SGLT2 inhibitors, finerenone, or other drug classes. However, these composites were diverse and assessed in a broad range of patients, hindering comparisons.

Clinically objective independent outcomes, such as kidney failure and ACM, were more consistently defined. Of 32 trials reporting incidences of kidney failure, seven observed significant risk reductions following treatment. These included a small trial of losartan $(n=751)$ in patients with T2D [61] and four smaller trials of losartan, benazepril, and ramipril $(n=84-436)$ in patients without T2D [112, 113, 115, 118], all published before 2008 . Consequently, RAAS inhibition became the standard of care for patients with CKD [4]. However, there had been a lack of success in developing new agents to augment RAAS inhibitors, delay progression, and improve outcomes, with trials of other drug classes scarcely meeting their primary endpoints until recently. Two large trials ( $n=2152$ and 2202) published onwards of 2019 demonstrated significant 
reductions in the risk of kidney failure among patients with UACR $\geq 200 \mathrm{mg} / \mathrm{g}$ treated with SGLT2 inhibitors $[25,27]$. While the CREDENCE trial of canagliflozin only enrolled patients with T2D, the DAPA-CKD trial of dapagliflozin showed that kidney-protective effects from SGLT2 inhibition could be extended to patients with or without T2D [25]. A significant reduction in ACM observed in the same trial of dapagliflozin is the only example of a marked prolongation of survival reported to date in patients with CKD [25], and evidence from a recent systematic review confirms that well-designed clinical trials are required to optimize existing treatments to meet this unmet need [125].

Kidney failure and other clinical outcomes develop late in $C K D$, requiring trials with relatively long durations to enroll large patient populations [10]. Surrogate endpoints can be used to monitor disease progression and evaluate treatments in earlier stages of CKD [10, 126-129]. However, this review identified a diverse range of surrogate endpoints, including specific eGFR changes from baseline (33.7\%), final eGFR values at end of follow-up (28.1\%), eGFR slopes (16.9\%), and percentage eGFR declines from baseline (12.4\%). Future clinical trials evaluating new treatments for patients in the earlier stages of CKD may therefore benefit from the standardization of surrogate endpoints.

While it has been shown elsewhere that HRQoL diminishes with progression of CKD $[5,6]$, this review highlights the paucity of data showing that improvements with treatment are accompanied by improvements in HRQoL. Only five trials $(5.6 \%)$ were identified that assessed HRQoL during treatment, with significant improvements limited to a trial of a hydrochloric acid binder for patients with metabolic acidosis [104]. Difficulties capturing changes in HRQoL, including the number of instruments used and differences in their sensitivities, have been highlighted recently [6].

This review has several limitations, including the exclusion of non-English-language publications and of trials enrolling patients without albuminuria. Phase was not reported in 51.7\% of trials, and it is possible that some phase 2 trials were included against eligibility criteria. A "higher" risk of bias was identified for $35 \%$ of trials that were not double blind. Finally, eligibility criteria were broad and this review included patients with any stage of CKD, with or without T2D, and treated with any drug class since 1990. CKD etiologies differed markedly between patients with T2D and without T2D, and a diverse range of comparators was also identified. Surrogate and clinically objective measurements of declining kidney function and treatment efficacy have also evolved over time, and 57 different composite outcomes were identified. Given the breadth and diversity of the data acquired, the performance of a metaanalysis was considered to be infeasible.

\section{CONCLUSION}

Until recently, only RAAS inhibitors had shown that they could delay CKD progression and reduce the risk of kidney failure; however, this evidence was generated in just one small trial of patients with T2D and four smaller trials of patients without T2D. Contemporary data from the CREDENCE, DAPA-CKD, and FIDELIO-DKD trials suggest that adding an appropriate SGLT2 inhibitor or finerenone on top of standard of care RAAS inhibition can significantly improve a range of both kidney and cardiovascular outcomes in patients with or without T2D. Moreover, data from DAPA-CKD suggest that dapagliflozin added to standard of care RAAS inhibition can significantly decrease all-cause mortality in patients with or without T2D. Given the morbidity and mortality burden of CKD, the impact of CKD progression on HRQoL and healthcare costs, and the increasing prevalence of risk factors such as hypertension and diabetes in aging populations, these new drug classes potentially have an important role in the future treatment and management of CKD.

\section{ACKNOWLEDGMENTS}

Funding. Development of this manuscript and all associated publication costs, including 
the journal's Rapid Service and Open Access Fees, were supported by AstraZeneca.

Medical Writing, Editorial, and Other Assistance. Medical writing and editorial support was provided by Matthew Young, DPhil, and Rachael Cazaly (Core, London, UK), supported by AstraZeneca according to Good Publication Practice guidelines (https://www. acpjournals.org/doi/10.7326/M15-0288).

Authorship. All named authors meet the International Committee of Medical Journal Editors (ICMJE) criteria for authorship for this article, take responsibility for the integrity of the work as a whole, and have given their approval for this version to be published.

Author Contributions. All authors contributed to the data interpretation, critically reviewed the manuscript, approved the final version, and accept accountability for the overall work. Study design was performed by Juan Jose Garcia Sanchez, Juliette Thompson, Glen James, Stephen Nolan, Naveen Rao, Bergur V. Stefansson, Alyshah Abdul Sultan, and Eric T. Wittbrodt. Data analyses were performed by Juan Jose Garcia Sanchez and Juliette Thompson. Ultimate responsibility for opinions, conclusions, and data interpretation lies with the authors.

Prior Presentation. Data presented in this article were also presented at the American Society of Nephrology Kidney Week meeting, October 22-25, 2020 (poster: PO0570).

Disclosures. Juan Jose Garcia Sanchez, Naveen Rao, Elisabeth Sörstadius, Glen James, Stephen Nolan, Eric T. Wittbrodt, Alyshah Abdul Sultan, Bergur V. Stefansson, and Dan Jackson are employees and shareholders of AstraZeneca. Juliette Thompson, David A. Scott, Rachel Evans, and Keith R. Abrams are partners/employees of Visible Analytics Ltd, which conducted this systematic review and received consultancy fees and expenses from AstraZeneca.
Compliance with Ethics Guidelines. This article is based on previously conducted studies and does not contain any new studies with human participants or animals performed by any of the authors.

Open Access. This article is licensed under a Creative Commons Attribution-NonCommercial 4.0 International License, which permits any non-commercial use, sharing, adaptation, distribution and reproduction in any medium or format, as long as you give appropriate credit to the original author(s) and the source, provide a link to the Creative Commons licence, and indicate if changes were made. The images or other third party material in this article are included in the article's Creative Commons licence, unless indicated otherwise in a credit line to the material. If material is not included in the article's Creative Commons licence and your intended use is not permitted by statutory regulation or exceeds the permitted use, you will need to obtain permission directly from the copyright holder. To view a copy of this licence, visit http:// creativecommons.org/licenses/by-nc/4.0/.

\section{REFERENCES}

1. Jager KJ, Kovesdy C, Langham R, Rosenberg M, Jha $\mathrm{V}$, Zoccali C. A single number for advocacy and communication-worldwide more than 850 million individuals have kidney diseases. Nephrol Dial Transplant. 2019;34(11):1803-5.

2. GBD Chronic Kidney Disease Collaboration. Global, regional, and national burden of chronic kidney disease, 1990-2017: a systematic analysis for the Global Burden of Disease Study 2017. Lancet. 2020;395(10225):709-33.

3. United States Renal Data System. 2020 USRDS annual data report: epidemiology of kidney disease in the United States National Institutes of Health, National Institute of Diabetes and Digestive and Kidney Diseases, Bethesda, MD [updated, 2020]. https://adr.usrds.org/2020. Accessed 6 Dec 2021.

4. KDIGO. KDIGO 2012 clinical practice guideline for the evaluation and management of chronic kidney disease. Kidney Int Suppl. 2012;3(1):1-150. 
5. Elshahat S, Cockwell P, Maxwell AP, Griffin M, $\mathrm{O}^{\prime}$ Brien T, O'Neill C. The impact of chronic kidney disease on developed countries from a health economics perspective: a systematic scoping review. PLoS One. 2020;15(3):e0230512.

6. Cooper JT, Lloyd A, Sanchez JJG, Sorstadius E, Briggs A, McFarlane P. Health related quality of life utility weights for economic evaluation through different stages of chronic kidney disease: a systematic literature review. Health Qual Life Outcomes. 2020;18(1):310.

7. Olufade T, Lamerato L, Sanchez JJG, et al. Clinical outcomes and healthcare resource utilization in a real-world population reflecting the DAPA-CKD trial participants. Adv Ther. 2021;38:1352-63.

8. Darlington O, Dickerson C, Evans M, et al. Costs and healthcare resource use associated with risk of cardiovascular morbidity in patients with chronic kidney disease: evidence from a systematic literature review. Adv Ther. 2021;38:994-1010.

9. Murton M, Goff-Leggett D, Bobrowska A, et al. Burden of chronic kidney disease by KDIGO categories of glomerular filtration rate and albuminuria: a systematic review. Adv Ther. 2021;38(1):180-200.

10. Perkovic V, Craig JC, Chailimpamontree W, et al. Action plan for optimizing the design of clinical trials in chronic kidney disease. Kidney Int Suppl. 2017;7(2):138-44.

11. Neuen BL, Young T, Heerspink HJL, et al. SGLT2 inhibitors for the prevention of kidney failure in patients with type 2 diabetes: a systematic review and meta-analysis. Lancet Diabetes Endocrinol. 2019;7(11):845-54.

12. Neal B, Perkovic V, Matthews DR. Canagliflozin and cardiovascular and renal events in type 2 diabetes. N Engl J Med. 2017;377(21):2099.

13. Zinman B, Wanner C, Lachin JM, et al. Empagliflozin, cardiovascular outcomes, and mortality in type 2 diabetes. N Engl J Med. 2015;373(22): 2117-28.

14. Wiviott SD, Raz I, Bonaca MP, et al. Dapagliflozin and cardiovascular outcomes in type 2 diabetes. N Engl J Med. 2019;380(4):347-57.

15. Kosiborod M, Cavender MA, Fu AZ, et al. Lower risk of heart failure and death in patients initiated on sodium-glucose cotransporter-2 inhibitors versus other glucose-lowering drugs: the CVD-REAL study (Comparative Effectiveness of Cardiovascular Outcomes in New Users of Sodium-Glucose Cotransporter-2 Inhibitors). Circulation. 2017;136(3): 249-59.
16. McMurray JJV, Solomon SD, Inzucchi SE, et al. Dapagliflozin in patients with heart failure and reduced ejection fraction. $\mathrm{N}$ Engl $\mathrm{J}$ Med. 2019;381(21):1995-2008.

17. Packer M, Anker SD, Butler J, et al. Cardiovascular and renal outcomes with empagliflozin in heart failure. N Engl J Med. 2020. https://doi.org/10. 1056/NEJMoa1911303.

18. Higgins JPT, Thomas J, Chandler J, et al., editors. Cochrane handbook for systematic reviews of interventions. 2nd ed. Chichester: Wiley; 2019.

19. Centre for Reviews Dissemination. Systematic reviews. York: CRD, York Publishing Services Ltd; 2009.

20. National Institute for Health and Care Excellence. Guide to the methods of technology appraisal 2013 London. https://www.ncbi.nlm.nih.gov/pubmed/ 27905712. Accessed 6 Dec 2021.

21. Scottish Intercollegiate Guidelines Network. Search filters. https://www.sign.ac.uk/what-we-do/ methodology/search-filters/. Accessed 6 Dec 2021.

22. Cochrane. Embase: Cochrane. https://work. cochrane.org/embase. Accessed 4 Nov 2020.

23. Halfpenny NJA, Scott DA, Thompson JC, Gurung B, Quigley JM. A practical approach to predict expansion of evidence networks: a case study in treatment-naive advanced melanoma. Melanoma Res. 2019;29(1):13-8.

24. National Institute for Health and Care Excellence. Single technology appraisal: user guide for company evidence submission template. Process and methods [PMG24] 2017. https://www.nice.org.uk/ process/pmg24/chapter/instructions-forcompanies. Accessed 6 Dec 2021.

25. Heerspink HJL, Stefansson BV, Correa-Rotter R, et al. Dapagliflozin in patients with chronic kidney disease. N Engl J Med. 2020;383:1436-46.

26. Bakris GL, Agarwal R, Anker SD, et al. Effect of finerenone on chronic kidney disease outcomes in type 2 diabetes. N Engl J Med. 2020;383(23): 2219-29.

27. Perkovic V, Jardine MJ, Neal B, et al. Canagliflozin and renal outcomes in type 2 diabetes and nephropathy. N Engl J Med. 2019;380(24): 2295-306.

28. Mahaffey KW, Jardine MJ, Bompoint S, et al. Canagliflozin and cardiovascular and renal outcomes in type 2 diabetes mellitus and chronic kidney disease in primary and secondary 
cardiovascular prevention groups. Circulation. 2019;140(9):739-50.

29. Jardine MJ, Zhou Z, Mahaffey KW, et al. Renal, cardiovascular, and safety outcomes of canagliflozin by baseline kidney function: a secondary analysis of the CREDENCE randomized trial. J Am Soc Nephrol. 2020;31(5):1128-39.

30. Liu M, Li F, Liang M, Rao X. Effects of aldose reductase inhibitors on renal blood flow parameters in patients with early diabetic nephropathy. J Diabetes Complications. 2020;34(9):107620.

31. Yagoglu AI, Dizdar OS, Erdem S, Akcakaya B, Gunal AI. The effect of linagliptin on renal progression in type-2 diabetes mellitus patients with chronic kidney disease: a prospective randomized controlled study. Nefrologia. 2020;40(6):664-71.

32. Allegretti AS, Zhang W, Zhou W, et al. Safety and effectiveness of bexagliflozin in patients with type 2 diabetes mellitus and stage $3 \mathrm{a} / 3 \mathrm{~b}$ CKD. Am J Kidney Dis. $2019 ; 74(3): 328-37$.

33. Pollock C, Stefansson B, Reyner D, et al. Albuminuria-lowering effect of dapagliflozin alone and in combination with saxagliptin and effect of dapagliflozin and saxagliptin on glycaemic control in patients with type 2 diabetes and chronic kidney disease (DELIGHT): a randomised, double-blind, placebo-controlled trial. Lancet Diabetes Endocrinol. 2019;7(6):429-41.

34. Rosenstock J, Perkovic V, Johansen OE, et al. Effect of linagliptin vs placebo on major cardiovascular events in adults with type 2 diabetes and high cardiovascular and renal risk: the CARMELINA randomized clinical trial. JAMA. 2019;321(1):69-79.

35. Fioretto P, Del Prato S, Buse JB, et al. Efficacy and safety of dapagliflozin in patients with type 2 diabetes and moderate renal impairment (chronic kidney disease stage 3A): The DERIVE Study. Diabetes Obes Metab. 2018;20(11):2532-40.

36. Grunberger G, Camp S, Johnson J, et al. Ertugliflozin in patients with stage 3 chronic kidney disease and type 2 diabetes mellitus: the VERTIS RENAL randomized study. Diabetes Ther. 2018;9(1): 49-66.

37. Tuttle KR, Lakshmanan MC, Rayner B, et al. Dulaglutide versus insulin glargine in patients with type 2 diabetes and moderate-to-severe chronic kidney disease (AWARD-7): a multicentre, open-label, randomised trial. Lancet Diabetes Endocrinol. 2018;6(8):605-17.

38. Groop PH, Cooper ME, Perkovic V, et al. Linagliptin and its effects on hyperglycaemia and albuminuria in patients with type 2 diabetes and renal dysfunction: the randomized MARLINA-T2D trial. Diabetes Obes Metab. 2017;19(11):1610-9.

39. Yoon SA, Han BG, Kim SG, et al. Efficacy, safety and albuminuria-reducing effect of gemigliptin in Korean type 2 diabetes patients with moderate to severe renal impairment: a 12-week, double-blind randomized study (the GUARD Study). Diabetes Obes Metab. 2017;19(4):590-8.

40. Han SY, Yoon SA, Han BG, et al. Comparative efficacy and safety of gemigliptin versus linagliptin in type 2 diabetes patients with renal impairment: a 40-week extension of the GUARD randomized study. Diabetes Obes Metab. 2018;20(2):292-300.

41. Davies MJ, Bain SC, Atkin SL, et al. Efficacy and safety of liraglutide versus placebo as add-on to glucose-lowering therapy in patients with type 2 diabetes and moderate renal impairment (LIRARENAL): a randomized clinical trial. Diabetes Care. 2016;39(2):222-30.

42. Barnett AH, Mithal A, Manassie J, et al. Efficacy and safety of empagliflozin added to existing antidiabetes treatment in patients with type 2 diabetes and chronic kidney disease: a randomised, double-blind, placebo-controlled trial. Lancet Diabetes Endocrinol. 2014;2(5):369-84.

43. Kohan DE, Fioretto P, Tang W, List JF. Long-term study of patients with type 2 diabetes and moderate renal impairment shows that dapagliflozin reduces weight and blood pressure but does not improve glycemic control. Kidney Int. 2014;85(4):962-71.

44. Yale JF, Bakris G, Cariou B, et al. Efficacy and safety of canagliflozin over 52 weeks in patients with type 2 diabetes mellitus and chronic kidney disease. Diabetes Obes Metab. 2014;16(10):1016-27.

45. Yale JF, Bakris G, Cariou B, et al. Efficacy and safety of canagliflozin in subjects with type 2 diabetes and chronic kidney disease. Diabetes Obes Metab. 2013;15(5):463-73.

46. Shikata K, Haneda M, Ninomiya T, et al. Randomized trial of an intensified, multifactorial intervention in patients with advanced-stage diabetic kidney disease: Diabetic Nephropathy Remission and Regression Team Trial in Japan (DNETT-Japan). J Diabetes Investig. 2021;12(2):207-16.

47. Heerspink HJL, Parving HH, Andress DL, et al. Atrasentan and renal events in patients with type 2 diabetes and chronic kidney disease (SONAR): a double-blind, randomised, placebo-controlled trial. Lancet. 2019;393(10184):1937-47.

48. Chen Y, Liu P, Chen X, Li Y, Zhang F, Wang Y. Effects of different doses of irbesartan combined with spironolactone on urinary albumin excretion 
rate in elderly patients with early type 2 diabetic nephropathy. Am J Med Sci. 2018;355(5):418-24.

49. Scheele W, Diamond S, Gale J, et al. Phosphodiesterase type 5 inhibition reduces albuminuria in subjects with overt diabetic nephropathy. J Am Soc Nephrol. 2016;27(11):3459-68.

50. Han SJ, Kim HJ, Kim DJ, et al. Effects of pentoxifylline on proteinuria and glucose control in patients with type 2 diabetes: a prospective randomized double-blind multicenter study. Diabetol Metab Syndr. 2015;7:64.

51. Navarro-González JF, Mora-Fernández C, Muros de Fuentes $M$, et al. Effect of pentoxifylline on renal function and urinary albumin excretion in patients with diabetic kidney disease: the PREDIAN trial. J Am Soc Nephrol. 2015;26(1):220-9.

52. Pan Y, Qiao QY, Pan LH, et al. Losartan reduces insulin resistance by inhibiting oxidative stress and enhancing insulin signaling transduction. Exp Clin Endocrinol Diabetes. 2015;123(3):170-7.

53. Fried LF, Emanuele N, Zhang JH, et al. Combined angiotensin inhibition for the treatment of diabetic nephropathy. N Engl J Med. 2013;369(20): 1892-903.

54. Palevsky PM, Zhang JH, Seliger SL, Emanuele N, Fried LF, VA NEPHRON-D Study. Incidence, severity, and outcomes of AKI associated with dual reninangiotensin system blockade. Clin J Am Soc Nephrol. 2016;11(11):1944-53.

55. Lewis EJ, Greene T, Spitalewiz S, et al. Pyridorin in type 2 diabetic nephropathy. J Am Soc Nephrol. 2012;23(1):131-6.

56. Imai E, Chan JC, Ito S, et al. Effects of olmesartan on renal and cardiovascular outcomes in type 2 diabetes with overt nephropathy: a multicentre, randomised, placebo-controlled study. Diabetologia. 2011;54(12):2978-86.

57. Mann JFE, Green D, Jamerson K, et al. Avosentan for overt diabetic nephropathy. J Am Soc Nephrol. 2010;21(3):527-35.

58. Bakris G, Burgess E, Weir M, Davidai G, Koval S, AMADEO Study Investigators. Telmisartan is more effective than losartan in reducing proteinuria in patients with diabetic nephropathy. Kidney Int. 2008;74(3):364-9.

59. Barnett AH, Bain SC, Bouter P, et al. Angiotensinreceptor blockade versus converting-enzyme inhibition in type 2 diabetes and nephropathy. $\mathrm{N}$ Engl J Med. 2004;351(19):1952-61.
60. Marre M, Lievre M, Chatellier G, Mann JF, Passa P, Ménard J. Effects of low dose ramipril on cardiovascular and renal outcomes in patients with type 2 diabetes and raised excretion of urinary albumin: randomised, double blind, placebo controlled trial (the DIABHYCAR study). BMJ. 2004;328(7438):495.

61. Brenner BM, Cooper ME, de Zeeuw D, et al. Effects of losartan on renal and cardiovascular outcomes in patients with type 2 diabetes and nephropathy. N Engl J Med. 2001;345(12):861-9.

62. Lewis EJ, Hunsicker LG, Clarke WR, et al. Renoprotective effect of the angiotensin-receptor antagonist irbesartan in patients with nephropathy due to type 2 diabetes. N Engl J Med. 2001;345(12): 851-60.

63. Atkins RC, Briganti EM, Lewis JB, et al. Proteinuria reduction and progression to renal failure in patients with type 2 diabetes mellitus and overt nephropathy. Am J Kidney Dis. 2005;45(2):281-7.

64. Berl T, Hunsicker LG, Lewis JB, et al. Cardiovascular outcomes in the Irbesartan Diabetic Nephropathy Trial of patients with type 2 diabetes and overt nephropathy. Ann Intern Med. 2003;138(7):542-9.

65. Chaturvedi N. Randomised placebo-controlled trial of lisinopril in normotensive patients with insulindependent diabetes and normoalbuminuria or microalbuminuria. The EUCLID Study Group. Lancet. 1997;349(9068):1787-92.

66. Lewis EJ, Hunsicker LG, Bain RP, Rohde RD. The effect of angiotensin-converting-enzyme inhibition on diabetic nephropathy. $\mathrm{N}$ Engl $\mathrm{J}$ Med. 1993;329(20):1456-62.

67. Voroneanu L, Siriopol D, Dumea R, et al. Addition of silymarin to renin-angiotensin system blockers in normotensive patients with type 2 diabetes mellitus and proteinuria: a prospective randomized trial. Int Urol Nephrol. 2017;49(12):2195-204.

68. Endo K, Saiki A, Yamaguchi T, et al. Probucol suppresses initiation of chronic hemodialysis therapy and renal dysfunction-related death in diabetic nephropathy patients: Sakura study. J Atheroscler Thromb. 2013;20(5):494-502.

69. Rutter MK, Prais HR, Charlton-Menys V, et al. Protection against nephropathy in diabetes with atorvastatin (PANDA): a randomized double-blind placebo-controlled trial of high- vs. low-dose atorvastatin. Diabet Med. 2011;28(1):100-8.

70. Abe M, Maruyama N, Okada K, Matsumoto S, Matsumoto K, Soma M. Effects of lipid-lowering therapy with rosuvastatin on kidney function and oxidative stress in patients with diabetic nephropathy. J Atheroscler Thromb. 2011;18(11):1018-28. 
71. Endo K, Miyashita Y, Sasaki H, et al. Probucol delays progression of diabetic nephropathy. Diabetes Res Clin Pract. 2006;71(2):156-63.

72. Packham DK, Wolfe R, Reutens AT, et al. Sulodexide fails to demonstrate renoprotection in overt type 2 diabetic nephropathy. J Am Soc Nephrol. 2012;23(1):123-30.

73. de Zeeuw D, Akizawa T, Audhya P, et al. Bardoxolone methyl in type 2 diabetes and stage 4 chronic kidney disease. N Engl J Med. 2013;369(26): 2492-503.

74. Parving HH, Brenner BM, McMurray JJV, et al. Cardiorenal end points in a trial of aliskiren for type 2 diabetes. N Engl J Med. 2012;367(23): 2204-13.

75. Pfeffer MA, Burdmann EA, Chen CY, et al. A trial of darbepoetin alfa in type 2 diabetes and chronic kidney disease. N Engl J Med. 2009;361(21): 2019-32.

76. Nakamoto H, Yu XQ, Kim S, et al. Effects of sustained-release beraprost in patients with primary glomerular disease or nephrosclerosis: CASSIOPEIR study results. Ther Apher Dial. 2020;24(1):42-55.

77. Haynes R, Judge PK, Staplin N, et al. Effects of sacubitril/valsartan versus irbesartan in patients with chronic kidney disease: a randomized doubleblind trial. Circulation. 2018;138(15):1505-14.

78. Ameen, Kashif MA, Sumreen. To compare anti-albumin urea effects of valsartan alone with combination of valsartan and amlodipine in patients of chronic kidney disease. Pak J Med Sci. 2016;32(3): 613-6.

79. Hosoya T, Ohno I, Nomura S, et al. Effects of topiroxostat on the serum urate levels and urinary albumin excretion in hyperuricemic stage 3 chronic kidney disease patients with or without gout. Clin Exp Nephrol. 2014;18(6):876-84.

80. Ando K, Nitta K, Rakugi H, et al. Comparison of the antialbuminuric effects of benidipine and hydrochlorothiazide in renin-angiotensin system (RAS) inhibitor-treated hypertensive patients with albuminuria: the COSMO-CKD (COmbination Strategy on Renal Function of Benidipine or Diuretics TreatMent with RAS inhibitOrs in a Chronic Kidney Disease Hypertensive Population) study. Int J Med Sci. 2014;11(9):897-904.

81. Ando K, Ueshima K, Tanaka S, et al. Comparison of the antialbuminuric effects of L-/N-type and L-type calcium channel blockers in hypertensive patients with diabetes and microalbuminuria: the study of assessment for kidney function by urinary microalbumin in randomized (SAKURA) trial. Int J Med Sci. 2013;10(9):1209-16.

82. Wang W, Li L, Zhou Z, Gao J, Sun Y. Effect of spironolactone combined with angiotensin-converting enzyme inhibitors and/or angiotensin II receptor blockers on chronic glomerular disease. Exp Ther Med. 2013;6(6):1527-31.

83. Yasuda T, Endoh M, Suzuki D, et al. Effects of valsartan on progression of kidney disease in Japanese hypertensive patients with advanced, predialysis, chronic kidney disease: Kanagawa Valsartan Trial (KVT). Hypertens Res. 2013;36(3):240-6.

84. Abe M, Okada K, Maruyama N, et al. Benidipine reduces albuminuria and plasma aldosterone in mild-to-moderate stage chronic kidney disease with albuminuria. Hypertens Res. 2011;34(2):268-73.

85. Bakris GL, Sarafidis PA, Weir MR, et al. Renal outcomes with different fixed-dose combination therapies in patients with hypertension at high risk for cardiovascular events (ACCOMPLISH): a prespecified secondary analysis of a randomised controlled trial. Lancet. 2010;375(9721):1173-81.

86. Ruggenenti P, Perna A, Tonelli M, et al. Effects of add-on fluvastatin therapy in patients with chronic proteinuric nephropathy on dual renin-angiotensin system blockade: the ESPLANADE trial. Clin J Am Soc Nephrol. 2010;5(11):1928-38.

87. Abe M, Okada K, Maruyama N, et al. Comparison between the antiproteinuric effects of the calcium channel blockers benidipine and cilnidipine in combination with angiotensin receptor blockers in hypertensive patients with chronic kidney disease. Expert Opin Investig Drugs. 2010;19(9):1027-37.

88. Iino Y, Hayashi M, Kawamura T, et al. Renoprotective effect of losartan in comparison to amlodipine in patients with chronic kidney disease and hypertension-a report of the Japanese Losartan Therapy Intended for the Global Renal Protection in Hypertensive Patients (JLIGHT) study. Hypertens Res. 2004;27(1):21-30.

89. Maschio G, Alberti D, Janin G, et al. Effect of the angiotensin-converting-enzyme inhibitor benazepril on the progression of chronic renal insufficiency. The Angiotensin-Converting-Enzyme Inhibition in Progressive Renal Insufficiency Study Group. N Engl J Med. 1996;334(15):939-45.

90. Maschio G, Alberti D, Locatelli F, et al. Angiotensinconverting enzyme inhibitors and kidney protection: the AIPRI trial. The ACE Inhibition in Progressive Renal Insufficiency (AIPRI) Study Group. J Cardiovasc Pharmacol. 1999;33(Suppl 1):S16-20 (discussion S41-3). 
91. Kimura G, Kasahara M, Ueshima K, et al. Effects of atorvastatin on renal function in patients with dyslipidemia and chronic kidney disease: assessment of clinical usefulness in CKD patients with atorvastatin (ASUCA) trial. Clin Exp Nephrol. 2017;21(3):417-24

92. Suzuki H, Watanabe $Y$, Kumagai $H$, Shuto $H$. Comparative efficacy and adverse effects of the addition of ezetimibe to statin versus statin titration in chronic kidney disease patients. Ther Adv Cardiovasc Dis. 2013;7(6):306-15.

93. Baigent C, Landray MJ, Reith C, et al. The effects of lowering LDL cholesterol with simvastatin plus ezetimibe in patients with chronic kidney disease (Study of Heart and Renal Protection): a randomised placebo-controlled trial. Lancet. 2011;377(9784): 2181-92.

94. Haynes R, Lewis D, Emberson J, et al. Effects of lowering LDL cholesterol on progression of kidney disease. J Am Soc Nephrol. 2014;25(8):1825-33.

95. Fassett RG, Robertson IK, Ball MJ, Geraghty DP, Coombes JS. Effect of atorvastatin on kidney function in chronic kidney disease: a randomised double-blind placebo-controlled trial. Atherosclerosis. 2010;213(1):218-24.

96. Fassett RG, Robertson IK, Ball MJ, Geraghty DP, Coombes JS. Effects of atorvastatin on biomarkers of inflammation in chronic kidney disease. Clin Nephrol. 2014;81(2):75-85.

97. Cha RH, Kang SW, Park CW, et al. A randomized, controlled trial of oral intestinal sorbent AST-120 on renal function deterioration in patients with advanced renal dysfunction. Clin J Am Soc Nephrol. 2016;11(4):559-67.

98. Schulman G, Berl T, Beck GJ, et al. Randomized placebo-controlled EPPIC trials of AST-120 in CKD. J Am Soc Nephrol. 2015;26(7):1732-46.

99. Akizawa T, Asano Y, Morita S, et al. Effect of a carbonaceous oral adsorbent on the progression of CKD: a multicenter, randomized, controlled trial. Am J Kidney Dis. 2009;54(3):459-67.

100. Badve SV, Pascoe EM, Boudville N, et al. Effects of allopurinol on the progression of chronic kidney disease. N Engl J Med. 2020;382(26):2504-13.

101. Kimura K, Hosoya T, Uchida S, et al. Febuxostat therapy for patients with stage $3 \mathrm{CKD}$ and asymptomatic hyperuricemia: a randomized trial. Am J Kidney Dis. 2018;72(6):798-810.

102. Goicoechea M, De Vinuesa SG, Verdalles U, et al. Effect of allopurinol in chronic kidney disease progression and cardiovascular risk. Clin J Am Soc Nephrol. 2010;5(8):1388-93.

103. Tsubakihara Y, Gejyo F, Nishi S, et al. High target hemoglobin with erythropoiesis-stimulating agents has advantages in the renal function of non-dialysis chronic kidney disease patients. Ther Apher Dial. 2012;16(6):529-40.

104. Wesson DE, Mathur V, Tangri N, et al. Long-term safety and efficacy of veverimer in patients with metabolic acidosis in chronic kidney disease: a multicentre, randomised, blinded, placebo-controlled, 40-week extension. Lancet. 2019;394(10196):396-406.

105. Goicoechea M, de Vinuesa SG, Quiroga B, et al. Aspirin for primary prevention of cardiovascular disease and renal disease progression in chronic kidney disease patients: a multicenter randomized clinical trial (AASER study). Cardiovasc Drugs Ther. 2018;32(3):255-63.

106. Hayashi T, Maruyama S, Nangaku M, et al. Darbepoetin alfa in patients with advanced CKD without diabetes: randomized, controlled trial. Clin J Am Soc Nephrol. 2020;15(5):608-15.

107. Ando K, Ohtsu H, Uchida S, et al. Anti-albuminuric effect of the aldosterone blocker eplerenone in nondiabetic hypertensive patients with albuminuria: a double-blind, randomised, placebo-controlled trial. Lancet Diabetes Endocrinol. 2014;2(12):944-53.

108. Woo KT, Choong HL, Wong KS, et al. Aliskiren and losartan trial in non-diabetic chronic kidney disease. J Renin Angiotensin Aldosterone Syst. 2014;15(4):515-22.

109. Shen PC, He LQ, Yang XJ, Cao HX. Renal protection of losartan $50 \mathrm{mg}$ in normotensive Chinese patients with nondiabetic chronic kidney disease. J Investig Med. 2012;60(7):1041-7.

110. Bianchi S, Bigazzi R, Campese VM. Intensive versus conventional therapy to slow the progression of idiopathic glomerular diseases. Am J Kidney Dis. 2010;55(4):671-81.

111. Esnault VL, Brown EA, Apetrei E, et al. The effects of amlodipine and enalapril on renal function in adults with hypertension and nondiabetic nephropathies: a 3-year, randomized, multicenter, doubleblind, placebo-controlled study. Clin Ther. 2008;30(3):482-98.

112. Hou FF, Xie D, Zhang X, et al. Renoprotection of Optimal Antiproteinuric Doses (ROAD) study: a randomized controlled study of benazepril and losartan in chronic renal insufficiency. J Am Soc Nephrol. 2007;18(6):1889-98. 
113. Hou FF, Zhang X, Zhang GH, et al. Efficacy and safety of benazepril for advanced chronic renal insufficiency. N Engl J Med. 2006;354(2):131-40.

114. Ruggenenti P, Perna A, Loriga G, et al. Blood-pressure control for renoprotection in patients with non-diabetic chronic renal disease (REIN-2): multicentre, randomised controlled trial. Lancet. 2005;365(9463):939-46.

115. Agodoa LY, Appel L, Bakris GL, et al. Effect of ramipril vs amlodipine on renal outcomes in hypertensive nephrosclerosis: a randomized controlled trial. JAMA. 2001;285(21):2719-28.

116. Cinotti GA, Zucchelli PC, Collaborative Study Group. Effect of lisinopril on the progression of renal insufficiency in mild proteinuric non-diabetic nephropathies. Nephrol Dial Transplant. 2001;16(5):961-6.

117. Herlitz H, Harris K, Risler T, et al. The effects of an ACE inhibitor and a calcium antagonist on the progression of renal disease: the Nephros Study. Nephrol Dial Transplant. 2001;16(11):2158-65.

118. Ruggenenti P, Perna A, Gherardi G, et al. Renoprotective properties of ACE-inhibition in non-diabetic nephropathies with non-nephrotic proteinuria. Lancet. 1999;354(9176):359-64.

119. The GISEN Group (Gruppo Italiano di Studi Epidemiologici in Nefrologia). Randomised placebocontrolled trial of effect of ramipril on decline in glomerular filtration rate and risk of terminal renal failure in proteinuric, non-diabetic nephropathy. Lancet. 1997;349(9069):1857-63.

120. Stefoni S, Mosconi G, La Manna G, et al. Lowdosage ibopamine treatment in progressive renal failure: a long-term multicentre trial. Am J Nephrol. 1996;16(6):489-99.

121. Zucchelli P, Zuccala A, Borghi M, et al. Long-term comparison between captopril and nifedipine in the progression of renal insufficiency. Kidney Int. 1992;42(2):452-8.
122. Chue CD, Townend JN, Moody WE, et al. Cardiovascular effects of sevelamer in stage $3 \mathrm{CKD}$. J Am Soc Nephrol. 2013;24(5):842-52.

123. Ruggenenti P, Perna A, Benini R, et al. In chronic nephropathies prolonged ACE inhibition can induce remission: dynamics of time-dependent changes in GFR. J Am Soc Nephrol. 1999;10(5): 997-1006.

124. Levey AS, Eckardt KU, Dorman NM, et al. Nomenclature for kidney function and disease: report of a Kidney Disease: improving Global Outcomes (KDIGO) Consensus Conference. Kidney Int. 2020;97(6):1117-29.

125. Kim JY, Steingroever J, Lee KH, et al. Clinical interventions and all-cause mortality of patients with chronic kidney disease: an umbrella systematic review of meta-analyses. J Clin Med. 2020;9(2):394.

126. Grams ME, Sang Y, Ballew SH, et al. Evaluating glomerular filtration rate slope as a surrogate end point for ESKD in clinical trials: an individual participant meta-analysis of observational data. J Am Soc Nephrol. 2019;30(9):1746-55.

127. Greene T, Ying J, Vonesh EF, et al. Performance of GFR slope as a surrogate end point for kidney disease progression in clinical trials: a statistical simulation. J Am Soc Nephrol. 2019;30(9):1756-69.

128. Inker LA, Heerspink HJL, Tighiouart $H$, et al. GFR slope as a surrogate end point for kidney disease progression in clinical trials: a meta-analysis of treatment effects of randomized controlled trials. J Am Soc Nephrol. 2019;30(9):1735-45.

129. Levey AS, Gansevoort RT, Coresh J, et al. Change in albuminuria and GFR as end points for clinical trials in early stages of CKD: a scientific workshop sponsored by the National Kidney Foundation in collaboration with the US Food and Drug Administration and European Medicines Agency. Am J Kidney Dis. 2020;75(1):84-104. 